\title{
Effect of Agility and Perturbation Training on Pain, Balance and Functional Ability in Subjects with Patellofemoral Pain Syndrome
}

\author{
Kalpana', Mohan Kumar Muniyan ${ }^{2}$, A M R Suresh ${ }^{3}$, \\ Tapas Priyaranjan Behera ${ }^{4}$, Dimple Kashyap ${ }^{5}$ \\ ${ }^{1}$ Physiotherapist, Manipal Hospital, Old Airport road, Bengaluru, India \\ ${ }^{2}$ Incharge-Physiotherapy Deptt., Brookfield Hospital, Bengaluru, India. \\ ${ }^{3}$ Sr.Physiotherapist, Pandit Deendayal Upadhyaya National Institute for the Persons with Physical Disabilities \\ (Divyangjan), New Delhi, India. \\ ${ }^{4}$ Prosthetist and Orthotist, Pandit Deendayal Upadhyaya National Institute for the Persons with Physical \\ Disabilities (Divyangjan), New Delhi, India. \\ ${ }^{5}$ Physiotherapist, Deptt. of Physical Medicine and Rehabilitation, Kalawati Saran Children's Hospital, \\ New Delhi, India. \\ Corresponding Author: Kalpana
}

\begin{abstract}
Background: Agility and Perturbation training have been advocated to improve pain, balance and functional abilities in subjects with osteoarthritis of knee but effect of same on Patellofemoral pain have not been explored in studies. The above techniques would be helpful along with standard rehabilitation programs in reducing dynamic knee instability or improving dynamic stability upon return to high level physical activity and have an additive effect of reducing pain in OA knee.

Objective: The purpose of the study is to find the effect of Agility and Perturbation training on improvement of pain, balance and functional abilities in subject with Patellofemoral Pain Syndrome.

Method: A randomized controlled study with 40 individuals has been taken with patellofemoral pain syndrome. 20 subjects have been selected for control group and 20 subjects for study group. Outcome measures includes Kujala function scale, Y balance test and Numeric pain rating scale were measured before and immediately after the treatment.

Results: Analysis using Mann Whitney U Test and Independent $t$ between the groups found that when pre intervention means of NPRS, Composite score YBT and Kujala Score were compared there is a statistically significant difference between the groups. When post intervention means of NPRS and Kujala score were compared between the groups there is no statistically significant difference between the groups. When post intervention means of Composite score YBT were compared there is a statically significant difference.
\end{abstract}

Conclusion: The present study concludes that Agility and Perturbation training shown significant improvement of pain, function and balance in subject with Patellofemoral Pain Syndrome.

Key Words: Patellofemoral Pain Syndrome, Kujala function Scale, Y balance test.

\section{INTRODUCTION}

Patellofemoral pain syndrome (PFPS) is an overuse injury characterized by aching pain in the peripatellar area that is exacerbated by physical activities such as climbing stairs, squatting, jumping, and running and/or by sitting with the knees flexed for prolonged periods of time. The prevalence of this problem is high because it can occur in patients with a wide range of physical activity levels. ${ }^{1}$ The function of the $\mathrm{PF}$ joint can be characterized by a load/frequency distribution that defines a range of painless loading that is compatible 
with homeostasis of the joint tissues. If too little or excessive loading is placed across the joint, loss of tissue homeostasis can occur resulting in pain and other dysfunctions. The goal of operative and nonoperative treatment is therefore to restore the homeostasis of the PF joint. This can be achieved in the first place by a load restriction within the patient's reduced envelope of function. This 'overuse' of the $\mathrm{PF}$ joint (with loss of homeostasis as a consequence) can be the result of a variety of reasons. ${ }^{4}$

PFPS development is probably multifactorial with various functional disorders of the lower extremity. ${ }^{5}$ Several risk factors have been proposed as possible parameters involved in pathogenesis of PFPS. These risk factors are classified as intrinsic or extrinsic risk factors.

Extrinsic risk factors are related to factors outside human body, such as the type of sports activity, environmental conditions, and the surface and equipment used. Intrinsic risk factors relate more to individual characteristics. Some of these intrinsic risk factors are modifiable and may be addressed in the management of this disorder in clinical setting. Some modifiable risk factors play a role in the development and persistence of PFPS, including quadriceps weakness, specifically in vastus medialis obliquus (VMO), tightness of hamstring, tightness of iliopsoas, tightness of iliotibial band, tightness of gastrosoleus, hip muscles dysfunction, especially abductors and external rotators, foot over pronation, generalized joint laxity, limb length discrepancy, patellar malalignment and patellar hypermobility. ${ }^{6}$

Proprioceptive information from the active (muscular) and passive (osseous/ligamentous) systems contributes to the overall neuromuscular control of patellar tracking. Specifically, vastus medialis oblique (VMO) is believed to assist in maintaining patella position by applying a medial force vector to counteract the lateral pull of the larger vastus lateralis (VL). The onset of VMO activation relative to the VL is commonly delayed in individuals with PFPS during stair ascent and descent, in contrast to healthy controls where concurrent onset of the contraction of VMO and VL is the norm. ${ }^{10}$ However, functional movement depends not only on the acquisition of stimuli from peripheral mechanoreceptors in joints, muscles, and deep tissues but also on the regulation of this motion via agonist-antagonist muscle activation by the central nervous system. ${ }^{12}$

Due to lack of proprioception inputs in subjects with PFPS are prone for loss of balance and affect their overall function. ${ }^{13}$ Proprioceptive rehabilitation decreases the incidence of injury or improves the results of treatment. Proprioceptive deficiency has been shown to cause abnormal stress accumulation in the surrounding tissue by obstructing the movements and consequently contributes to the occurrence of further problems in the joint. ${ }^{11}$ Limited studies exist investigating the proprioception in patellofemoral disorders. Edin thought that alteration of the tensile forces in the surrounding tissue might cause abnormal joint position sense. Jensen et al showed the decreased thresholds for tactile and cold senses in patients with PFPS. Maker et al and Hazneci et al found deteriorated proprioception in patients with PFPS, however Kramer et al found no change in proprioceptive level. ${ }^{11}$ Poor proprioceptive status can be enhanced by a simple patellar taping technique. Clinicians using patellar taping need not apply a complex technique to achieve an improvement in proprioception. Healthy subjects with poor proprioception may be at enhanced risk for PFPS. As with other knee conditions, applying an external appliance such as tape may reduce the risk of injury by enhancing proprioception. ${ }^{14}$

Agility is to include whole-body change of direction as well as rapid movement and direction change of limbs. It requires quick reflexes, coordination, balance, speed, and correct response to the changing situations. Agility testing is generally confined to tests of physical 
components such as change of direction speed, or cognitive components such as anticipation and pattern recognition. ${ }^{16}$ The agility training techniques included side stepping, braiding (lateral stepping combined with forward and backward crossover steps), front crossover steps during forward ambulation, back crossover steps during backward ambulation, shuttle walking (forward and backward walking to and from designated markers), and a drill requiring multiple changes in direction in which the therapist provided hand signals at random to prompt the individual to change direction (forward and backward, right and left lateral steps, diagonally backward and forward) during walking. ${ }^{17}$ PFPS patients do not have normal control of lower limb movements and exhibit deficient neuromuscular parameters. It is also known that abnormalities of lower limb movement patterns during weight-bearing activities can directly affect referred pain.

Balance training has been defined as exercise designed to focus on postural awareness and equilibrium maintenance without changing the base of support and has been incorporated into a variety of training programs. There is a general consensus in the scientific community that balance training can improve postural stability, or the ability to maintain an upright posture under dynamic conditions, in a population with lower extremity injury such as an ACL tear. However, this has not been verified in populations with mechanically stable knees. ${ }^{19}$ A perturbation is any sudden changes in conditions that displace the body posture away from equilibrium. The perturbation can be sensory and mechanical. ${ }^{20}$ A sensory perturbation might be caused by altering of visual input, this might occur when a person's eyes are covered unexpectedly. Mechanical perturbation is displacements that involve direct changes in the relationship of centre of mass (COM) to the base of support (BOS). These displacements may be caused by movements of either body segments or the entire body. ${ }^{21}$
Perturbation training includes single leg stance or use of roller boards simple exercise progressed to complex helps protect the joint from painful loads and helps to restore the muscle power and ligament and damaged tissues around joint, lower extremity through coordination. ${ }^{22}$ In order to analyze the pain among the patient's complaints, the use of questionnaires for anterior knee pain has been used to monitor changes in patient's conditions and evaluate the effectiveness of treatment. Kujala can be an important tool in the attempt to characterize the symptoms involving the presence of PFPS, scoring which activities require greater stress from the individual and to his patellofemoral joint and assign them to functional assessment. ${ }^{23}$

The Kujala AKPS is a 13-item screening instrument designed to assess patellofemoral pain in adolescents and young adults, with a variable ordinal response format. The Kujala AKPS, is a well-recognized and highly respected instrument used within the fields of orthopedics and sports medicine. ${ }^{24}$ The items assessed in the questionnaire are patellar subluxation, claudication, pain, walking, climbing stairs and prolonged sitting with the knees flexed. It has a score from 0 to 100 points, where 100 means without pain and/or functional limitations and 0 means constant pain and various functional limitations. Categorized within each item are weighted and responses are summed to provide an overall index in which 100 represent "no disability" and 0 represent "maximum disability". Increase of at least 8-10 points on the Kujala scale represents improvements in the subject's perceived pain during functional activity. ${ }^{25}$

The numeric pain scale (NPS), a type of numeric rating scale used to measure pain severity, uses whole numbers. This format uses a discontinuous and segmented scale; thus, whole numbers are reported. The most common styles include a horizontal bar or line format. The line or bar is marked with whole numbers from 0 to 10 , however some scales may use different 
ranges such as 0 to 5 .The patient is asked to mark on the scale to rate their pain and then the number is recorded. The length of the line is not essential for this scale. ${ }^{26}$

$\mathrm{Y}$ Balance Test-YBT is a dynamic balance test. The YBT is essentially an instrumented version of the components of the SEBT, and it was developed to improve measurement repeatability and to standardize the performance of the test. The YBT incorporates reaching in 3 directions (anterior, posteromedial, and posterolateral) with the unsupported lower limb while in a single-limb stance on a centralized stance platform. In sports players, the YBT can be used for injury prediction and performance discrimination. The benefits of the YBT are that it has a standard protocol and high inter-rater (0.991.00) and intrarater $(0.850 .91)$ reliabilities. However, there was no previous study demonstrating the reliability of the YBT in middle-aged and older females. Nevertheless, the YBT can be used to test and train simultaneously, which is beneficial for the development of rehabilitation and training programs.

The relationship between the strength of the lower limb muscles and balance may be important for both the identification of older adults with an increased risk of falling and the development of fall-preventive training programs. Despite evidence demonstrating the importance of prevention of falling in older females, the relationship between the strength of the lower limbs and balance is not fully understood. ${ }^{27}$ Individuals with anterior left/right asymmetries greater than $4 \mathrm{~cm}$ on the YBT were 2.5 times more likely to sustain a lower extremity injury. ${ }^{28}$

\section{Need of the study}

Agility and perturbation exercises training are designed to challenge neuromuscular system helps to maintain balance and improve activities of daily living function. Agility and perturbation training techniques would be helpful along with standard rehabilitation programs in reducing dynamic knee instability or improving dynamic stability upon return to high level physical activity and have an additive effect of reducing pain in OA knee 22. But the effect of this training is not known on patellofemoral pain syndrome. The individuals with PFPS expose to activities that challenge the knee to potentially load during therapy may help them learn to deal with these loads when encountered in regular daily activity. Therefore there is a need to know the effect of agility and perturbation exercises on pain, balance and functional abilities in subjects with PFPS.

Hence, the purpose of the study is to find the effect of agility and perturbation training on improvement of pain, balance and functional abilities in subjects with patellofemoral pain syndrome.

\section{Research Question}

Does agility and perturbation training will improve pain, balance and functional abilities in subjects with Patellofemoral Pain Syndrome?

\section{AIMS AND OBJECTIVE OF THE STUDY}

Aim: The aim of the study is to determine the effect of Agility and Perturbation training on improvement of pain, balance and functional abilities in subject with Patellofemoral Pain Syndrome

Objective: To find the effect of Agility and Perturbation training on improvement of pain, balance and functional abilities in subject with Patellofemoral Pain Syndrome.

\section{HYPOTHESIS}

\section{Null hypothesis}

There will be no significant effect of Agility and Perturbation training on improvement of pain, balance and functional abilities in subject with Patellofemoral Pain Syndrome.

\section{Alternative hypothesis}

There will be a significant effect of Agility and Perturbation training on improvement of pain, balance and 
functional abilities in subject with Patellofemoral Pain Syndrome.

\section{METHODOLOGY}

\section{Study design:}

Randomized controlled study design with two groups: study group and control group.

\section{Study subjects:}

Syndrome.

Subjects with Patellofemoral Pain

\section{Sample size:}

Study was done on total of 40 subjects. 20 in each group.

$(n=40)$

\section{Sampling Method:}

\section{Study Duration:}

Simple Random sampling method.

4 weeks of interventions.

\section{Sample Selection:}

\section{Inclusion Criteria:}

- Clinical signs of patellofemoral pain syndrome such as retro patellar pain, crepitation, and pain with patellar grinding.

- Subjects with age of 20 to 40 years.

- Both male and female subjects.

- BMI 23.3 $\neg \pm 3.7$

- Pain more than 6 months.

- Presence of pain on step down from a 25 cm step or double leg squat.

- Sitting with knee bent greater than 15 minute.

- Pain more than $3 \mathrm{~cm}$ on NPRS scale.

- Individual with anterior left /right asymmetries greater than $4 \mathrm{~cm}$ on $\mathrm{Y}$ balance test.

\section{Exclusion Criteria}

- History of Ligament and meniscal injury.

- History of lower limb fractures.

- History of Post surgical condition of lower limb.

- Problem with vision.

- Osteoarthritis of knee.

- History of Patellar subluxation.

- Osteoporosis.
- Signs of nerve root compression.

- History of systemic, connective tissue or neurologic disorders.

\section{Materials used:}

1. Marker

2. Measuring tape

3. Wobble board

4. Foam roller

5. Kujala score sheet

6. Y balance score sheet

7. Numeric pain rating scale

\section{Procedure:}

As the study includes human subjects, ethical clearance was obtained before the commencement of the study. Subject who met the inclusion criteria was informed about the study and a written consent was taken. Subjects are randomly allocated and assigned to study group and control group. Study group were treated with agility and perturbation training with quadriceps sets. 3 sessions per week for 4 weeks.

\section{Procedure of intervention for study group:}

Agility training

Agility is rapid whole-body movement with change of velocity or direction in response to a stimulus. Agility training includes side stepping, braiding activities, and front and back crossover steps during forward ambulation, shuttle walking, multiple changes in direction during walking on therapist command.

1) Side stepping: Subject steps sideways, moving right to left approximately distance 10-20 feet, repeating 2 times in each direction for total 4 minutes.

Progression: The width of steps and the speed of steps had been progressed every 12 sessions. The activity was initiated on a level surface and progressed to side stepping over low obstacles when subject perform side stepping on level surface without difficulty. 
2) Braiding activities: subjects combine front and back crossover steps while moving laterally. During each activity subject was moving right to left and then left to right approximately 10-20 feet repeating 2 times in each direction for total 4 times.

Progression: Exercise progressed by increasing the width of steps and speed of steps every 1-2 sessions.

\section{3) Front and back cross over steps during} forward ambulation: Subject crosses one leg in front of other, alternating legs with each step, while walking forward approximately $10-20$ feet. The subject then walked backward to start position while crossing one leg behind the other, alternating legs with each step.

Progression: Progression of exercise was done by two repetitions. Begin with tandem cross over steps and progress to full crossover steps when the subject performance improved. The width of steps and the speed of steps were progressed every 1-2 sessions.

4) Shuttle walking: Plastic pylon markers were placed at distance of 5, 10, 15 feet. Subjects were asked to walk forward to first marker, then returns to start by walking backward. Subjects walked to 10 feet marker, then returns to 5 feet marker by walking backward. The subjects walked to 15 feet marker, returns to 10 feet marker by walking backward, then finishes by walking to 15 feet marker.

Progression: The activity was progressed by increasing width of steps and the speed of steps every 1-2 sessions.

5) Multiple changes in direction during walking on therapist command: Therapist directed the subjects to either walk forward, backward, sideways or diagonal by asking the subjects with hand signals. Changes in direction will be cued randomly by therapist.

Progression: Duration of exercise is approximately 30 seconds.

\section{Perturbation training}

Perturbation training includes single leg stance or use of roller boards.

1) Double leg foam balance activity: Subjects was stood on a soft foam surface with both feet on the ground. Therapist attempted to perturb patient balance in random fashion.

Progression: Duration of exercise is approximately 30 seconds. Difficulty was progressed as the subject improves by progression to ball catching with therapist perturbed subjects balance while standing on foam and progress to single leg support if tolerated without knee pain swelling and buckling.

2) Tilt board balance training: Subjects was stood on the tilt board with both feet on the board. The therapist perturbed the tilt board forward and backward and side to side directions for approximately 30 seconds.

Progression: The difficulty of the activity was progressed by adding ball catching during perturbation and progress to single leg support perturbation if the subjects tolerate single leg weight bearing without knee pain, swelling, buckling.

3) Roller board: Subjects was stood with one limb on a stationary platform and other on roller board. Therapist was perturbed roller board in multiple directions, at random and subjects attempts to resist perturbations. The activity lasts for 30 seconds. The activity was repeated by changing the limbs on platform and roller board.

Progression: The activity may begin with subjects in the semi seated position, with hip resting on the plinth if the subject has difficulty doing activity in full standing. It was progressed to full standing position if the subject was able to tolerate this position without pain. 


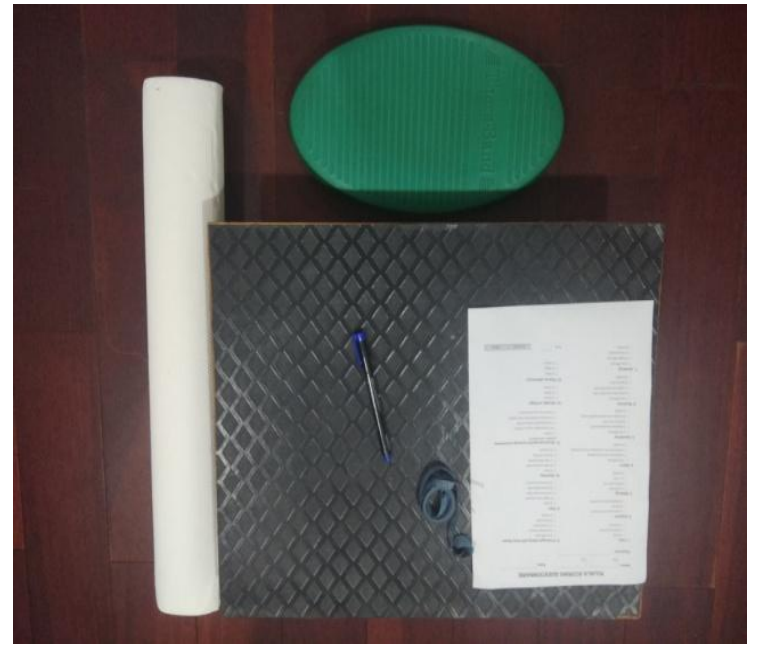

Figure 1: Material used

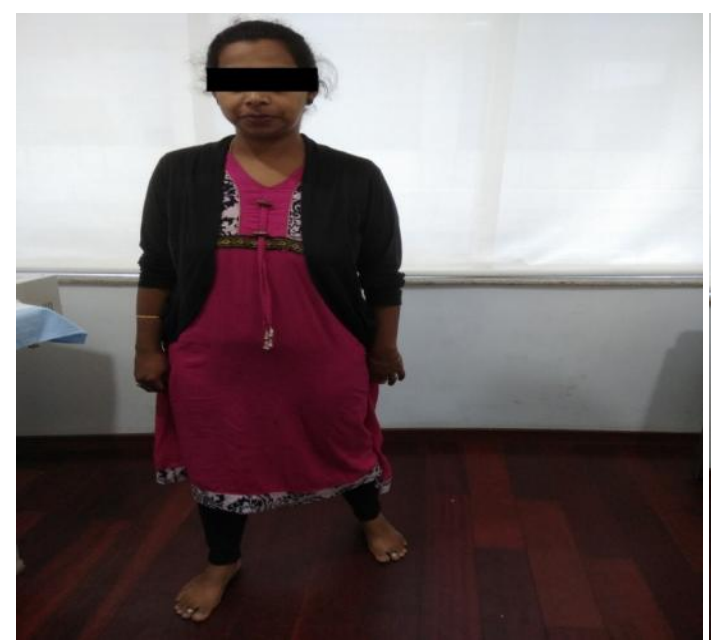

Figure3: Subject performing Braiding activity

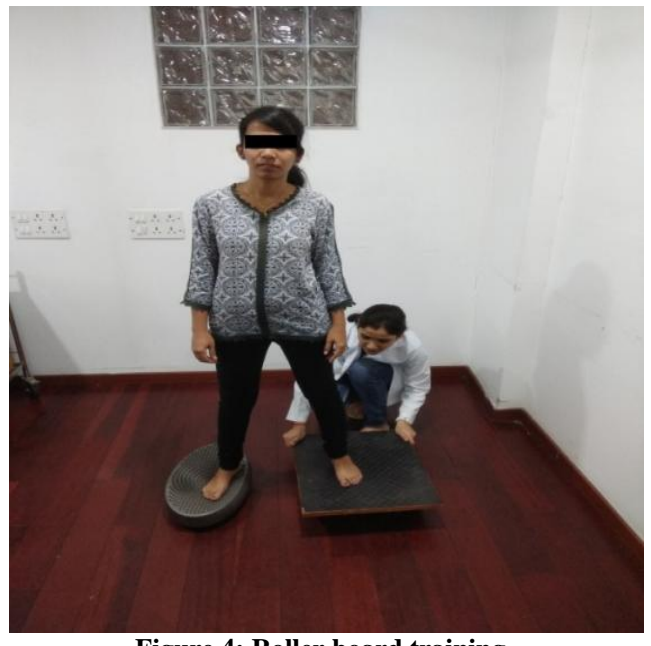

Figure 4: Roller board training

\section{Conventional exercises}

Conventional exercises were given for 3 sessions per week for 4 weeks. It includes semi squat, quadriceps isometric, terminal knee extension with elastic band, terminal knee extension in supine position,

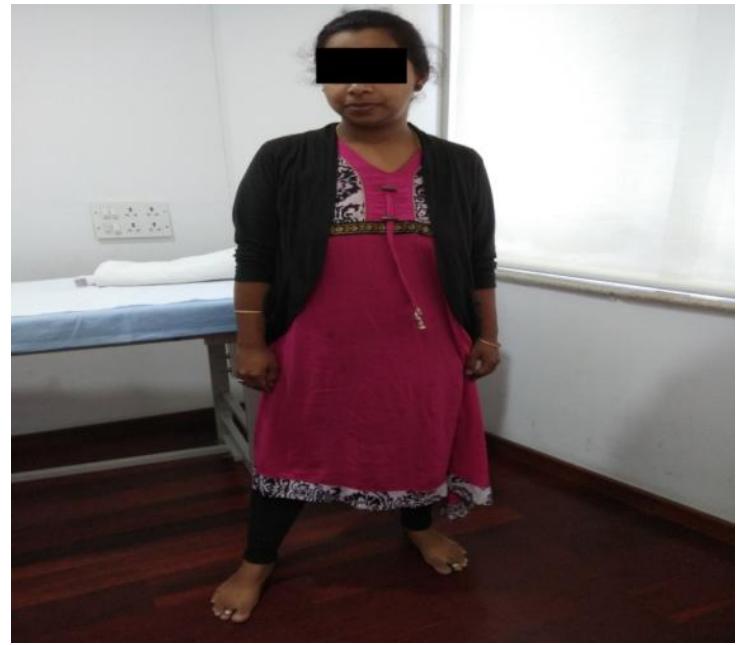

Figure 2: Subject performing Side stepping
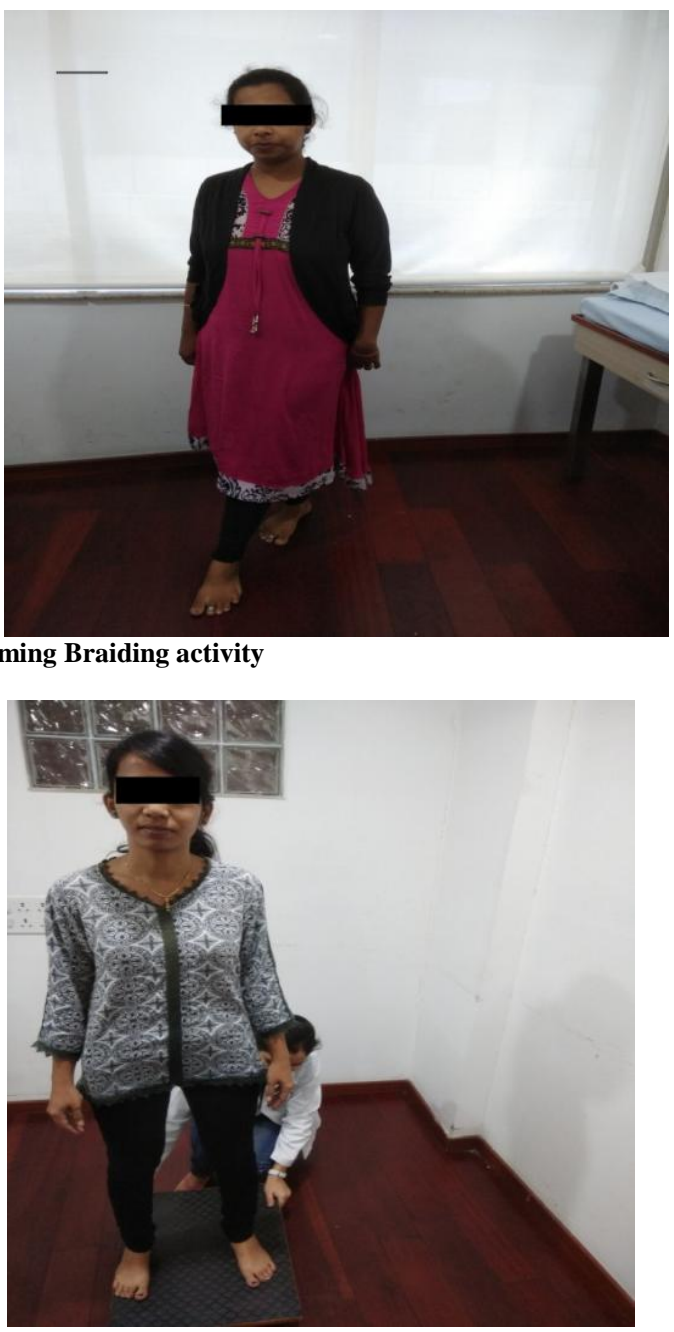

Figure 5: Tilt board balance training

and adductor squeeze in crook lying (squeeze the ball).

\section{1) Semi squat with hip adduction and} internal rotation:

The subject stood with his back supported on the wall with the feet 
approximately 1 foot away from the wall. Therapist directed the subject to lower his trunk on the wall with hip adduction and internal rotation and hold the position for 10seconds, then return back to the standing position. $(3 \times 15$ repetitions; 10 -second hold)

\section{2) Quadriceps isometric in supine position:}

The subject was positioned in the long sitting with knee extended. Therapist instructed the subject to isometrically contract the quadriceps as vigorously as possible without reproducing pain. The subject is instructed to hold the position for 10 seconds. $(3 \times 15$ repetitions; 10 -second hold)

\section{3) Terminal knee extension with elastic} band:

The subject was stood with feet shoulder width apart, facing towards the plinth and one end of the theraband attached around the knee and another to the plinth leg. The subject was asked to bend the knee to 300 and then straighten the leg to full extension against the resistance of band for 10 seconds, then return to starting position. $(3 \times 15$ repetitions; 10 -second hold $)$

\section{4) Terminal knee extension in supine position:}

Patient was positioned in the supine, keep towel under the knee, subject was asked to raise the leg while pressing the towel down and hold the position for 10seconds. $(3 \times 15$ repetitions; 10 -second hold)

\section{5) Adductor squeezes in crook lying (squeeze the ball):}

Subject was positioned in supine with knee and hip flexed, ask the subjects to hold the ball in between the knees. Therapist directed the subjects to press the ball as much as possible and hold the position for 10 seconds; subject could relax and return to the starting position. $(3 \times 15$ repetitions; 10 second hold).

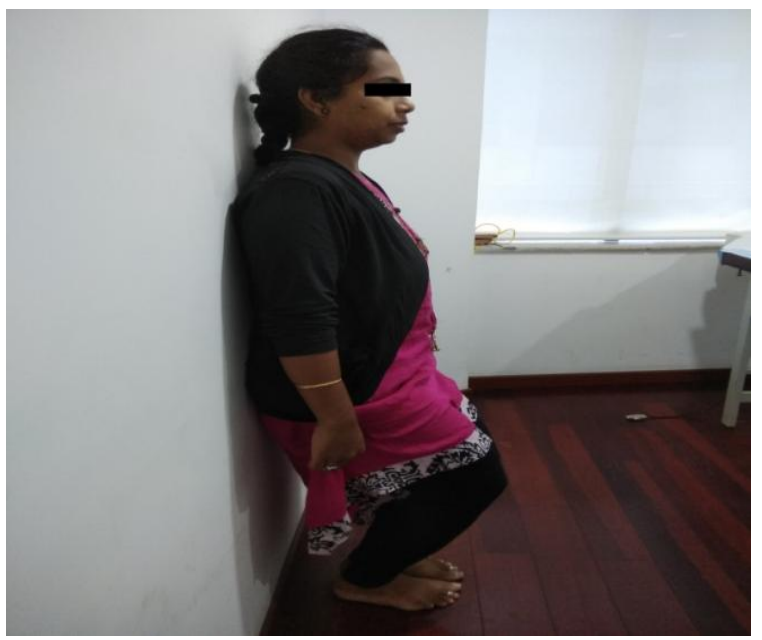

Figure 6: Semi squat with hip adduction and internal rotation
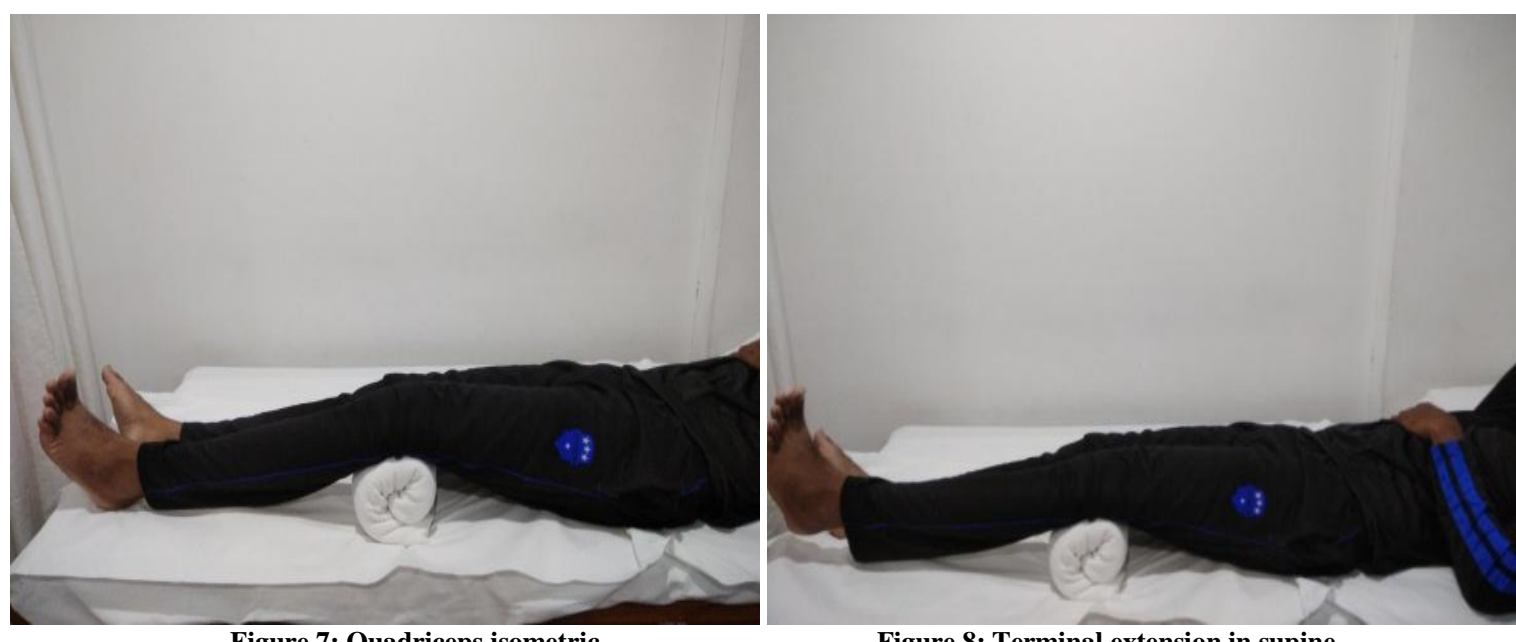

Figure 8: Terminal extension in supine 

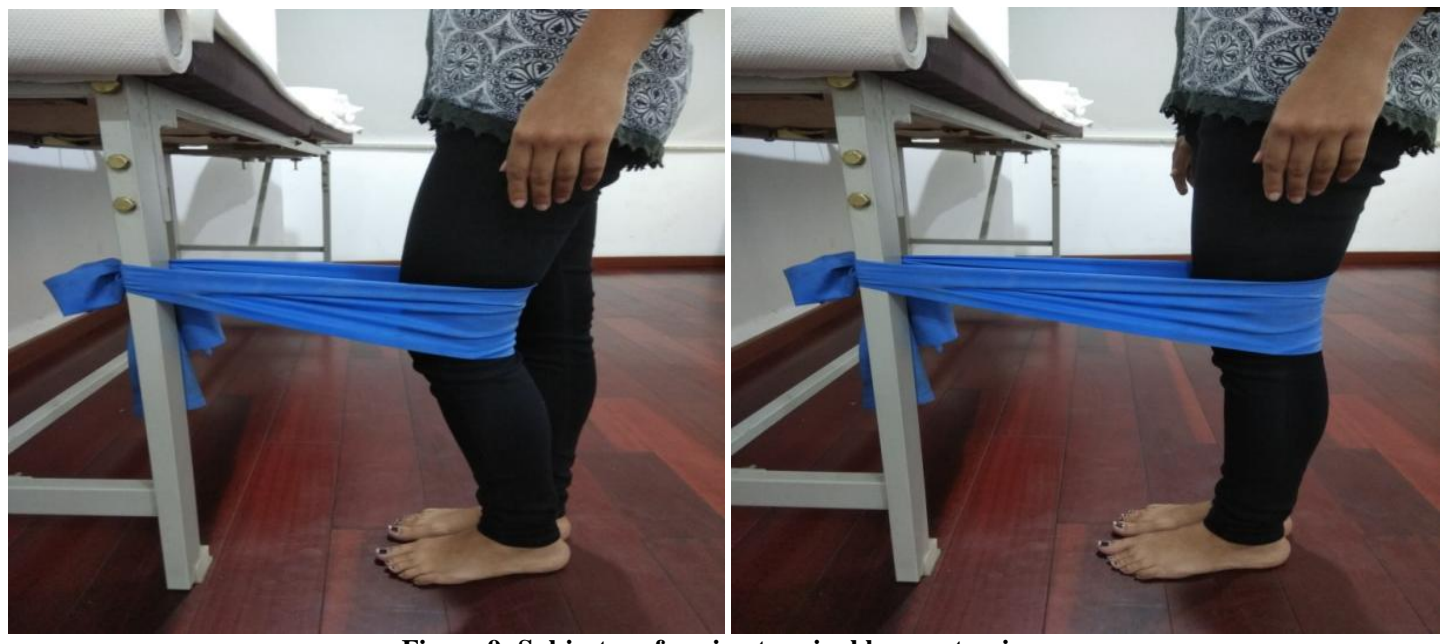

Figure 9: Subject performing terminal knee extension.

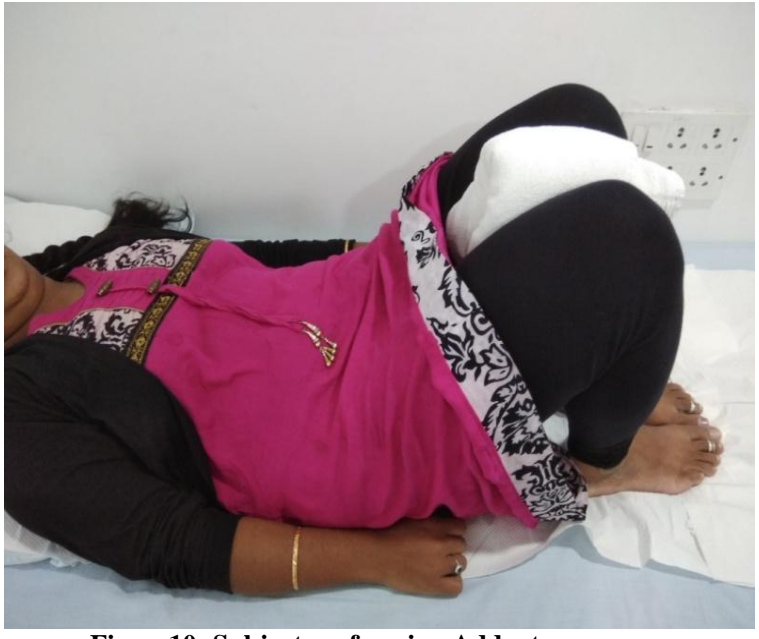

Figure10: Subject performing Adductor squeeze

\section{Procedure for Control group: Conventional exercises:}

Conventional exercises were given for 3 sessions per week for 4 weeks. It includes semi squat, quadriceps isometric, terminal knee extension with elastic band, terminal knee extension in supine position, and adductor squeeze in crook lying (squeeze the ball).

\section{Outcome measures}

All the subjects were assessed for outcome measures, where pain was measured using "Numeric pain rating scale", function ability was measured using "Kujala scale" questionnaire and balance was measured using "Y balance test" before and after 4 weeks of the intervention.

\section{Y balance test}

The Y-Balance Test (YBT) assesses the balance by challenging his postural control system in 3 (anterior, posteromedial, and posterolateral) of the 8 SEBT (star excursion balance test) directions and has been advocated as a method for assessing dynamic balance (requires strength, flexibility and proprioception).

Each subject had performed 6 practice trials to minimize the influence of a learning effect. The order of the practice trials was right anterior reach (6trials), left anterior reach (6trials), right posteromedial reach (6trials), left posteromedial reach (6trials), right posteromedial reach (6trials) and left posterolateral reach (6trials).

The formal testing trials were performed in the same order as the practice trials, with 3 trials performed in each direction. In each trail, the participants were instructed to reach as far as they could by using their reach foot while keeping their reach foot in contact with the reach indicator, and then return to the starting point while they maintained their balance on the stance limb.

The maximum reach distance was recorded to the nearest $0.5 \mathrm{~cm}$ in each reach trial. The maximum reach distance of the 3 formal trials in each direction was used for the analysis. The $\mathrm{Y}$ balance score was calculated by dividing the sum of the maximum reach distance in the anterior $(\mathrm{A})$, posteromedial (PM), and posterolateral (PL) 
directions by 3 times the limb length (LL) of the individual, then multiplied by 100 .

$\{[(\mathbf{A}+\mathbf{P M}+\mathbf{P L}) /(\mathbf{L L} \times \mathbf{3})] \times \mathbf{1 0 0}\}$.

Individuals with anterior left/right asymmetries greater than $4 \mathrm{~cm}$ on the YBT will be 2.5 times more likely to sustain a lower extremity injury.

$\mathrm{Y}$ balance test has good interrater test-retest reliability for both the maximal and average of 3 reaches. The measurement error will be minimized and interrater testretest reliability improved when the mean of 3 reach trials will used. ${ }^{56}$

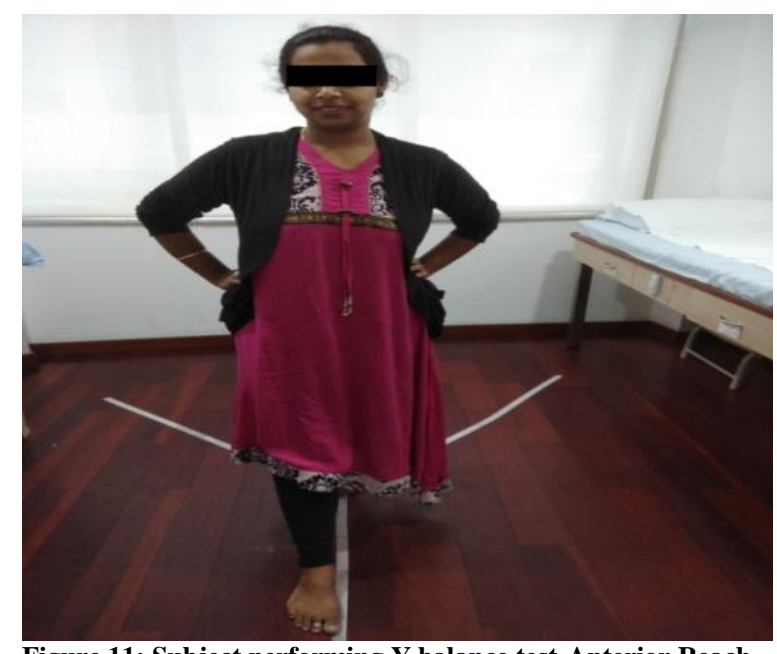

Figure 11: Subject performing Y balance test-Anterior Reach

\section{Kujala scale}

Anterior knee pain scale is frequently referred as Kujala scale. It's a 13item questionnaire including different items on pain related to function and activities. The items assessed in the questionnaire are patellar subluxation, claudication, pain, walking, climbing stairs and prolonged sitting with the knees flexed. It has a score from 0 to 100 points, where 100 means without pain and/or functional limitations and 0 means constant pain and various functional limitations. Categorized within each item are weighted and responses are summed to provide an overall index in which 100 represent "no disability" and 0 represent "maximum disability". An increase of at least 8-10 points on the Kujala scale represents improvements in the subject's perceived pain during functional activity. ${ }^{25}$
The four scoring formats of the Kujala scale were found to have high internal consistency (coef $=0.83$ to 0.91 ), equivalence across the short and long forms $(\mathrm{r}=0.98)$, acceptable standard errors of measurement ( 0.82 to 3.00 ), and moderate to high criterion related validity. The Kujala AKPS is a valid and reliable measure of anterior knee pain and appropriate for use as an epidemiologic screening tool. ${ }^{24}$

\section{Numeric pain rating scale}

The NPRS is a segmented numeric version of the visual analog scale (VAS) in which a respondent selects a whole number $(0-10$ integers) that best reflects the intensity of their pain. The common format is a horizontal bar or line. An 11-point numeric scale (NRS 11) with 0 representing one pain extreme (e.g., "no pain") and 10 representing the other pain extreme (e.g., "pain as bad as you can imagine" and "worst pain imaginable").

The patient is asked to make three pain ratings corresponding to current, best and worst pain experienced over past 24 hours. The average of three ratings is used to represent the patient's level of pain over the previous 2 hours.

0 : No pain

1-3: Mild pain

4-6: Moderate pain

7-10: Severe pain

The NPRS is a reliable and valid measure of pain intensity. ${ }^{57}$

\section{Data analysis \\ Statistical Methods:}

Descriptive statistical analysis has been carried out in the present study. Out Come measurements are measured for pain using "Numeric pain rating scale", functional ability using "Kujala scale" and balance using "Y balance test" and presented as mean $\pm \mathrm{SD}$. Significance is assessed at $5 \%$ level of significance with $p$ value 0.05 less than this is considered as statistically significant difference. 


\section{Statistical tests:}

- Pearson Chi-Square test and has been used to analyze the significant of basic characteristic of gender, age and side distribution of the subjects studied.

- Paired ' $\boldsymbol{t}$ ' test as a parametric and Wilcoxon signed rank test as a nonparametric test have been used to analysis the variables pre to post with calculation of percentage of change.

- Independent ' $t$ ' test as a parametric and Mann Whitney $U$ test as a nonparametric test have been used to compare the means of variables between groups with calculation of percentage of difference between the means.

\section{Statistical software:}

The Statistical software namely SPSS 16.0 (originally, Statistical Package for the Social Sciences, later modified to read Statistical Product and Service Solutions was released in its first version in 1968 after being developed by Norman H. Nie, Dale H. Bent and C. Hadlai Hull. It is now officially named "IBM SPSS Statistics" in its version 20.0), Stata 8.0, MedCalc 9.0.1 and Systat11.0 were used for the analysis of the data and Microsoft word and Excel have been used to generate graphs, tables etc. (Other software are PASW Statistics IBM SPSS Statistics)

\section{Interpretation of Significance $p$ value:}

- A p-value is calculated to assess whether trial results are likely to have occurred simply through chance (assuming that there is no real difference between after treatment and before, and assuming, of course, that the study was well conducted).

- The p-value is the probability that we would observe effects as big as those seen in the study if there was really no difference between the treatments. If $p$ is small, the findings are unlikely to have arisen by chance and we reject the idea that there is no difference between the two treatments (we reject the null hypothesis). If $\mathrm{p}$ is large, the observed difference is plausibly a chance finding and we do not reject the idea that there is no difference between the treatments. Note that we do not reject the idea, but we do not accept it either: we are simply unable to say one way or another until other factors have been considered.

But what do we mean by a 'small' pvalue (one small enough to cause us to reject the idea that there was really no difference)? By convention, p-values of less than 0.05 are considered 'small'. That is, if $\mathrm{p}$ is less than 0.05 there is a less than one in 20 chance that a difference as big as that seen in the study could have arisen by chance if there was really no true difference. With p-values this small (or smaller) we say that the results from the trial are statistically significant (unlikely to have arisen by chance). Smaller p-values (say $\mathrm{p}<0.01$ ) are sometimes called 'highly significant' because they indicate that the observed difference would happen less than once in a hundred times if there was really no true difference.

- Non-significance does not mean 'no effect'. Small studies will often report non-significance even when there are important, real effects which a large study would have detected.

- Statistical significance does not necessarily mean that the effect is real: by chance alone about one in 20 significant findings will be spurious.

- Statistically significant does not necessarily mean clinically important. It is the size of the effect that determines the importance, not the presence of statistical significance.

\section{Interpretation of confidence interval:}

- A confidence interval calculated for a measure of treatment effect shows the range within which the true treatment effect is likely to lie (subject to a number of assumptions).

- Confidence intervals are preferable to pvalues, as they tell us the range of possible effect sizes compatible with the 
data. P-values simply provide a cut-off beyond which we assert that the findings are 'statistically significant' (by convention, this is $\mathrm{p}<0.05$ ).

- A confidence interval that embraces the value of no difference between treatments indicates that the treatment under investigation is not significantly different from the control.

- Confidence intervals aid interpretation of clinical trial data by putting upper and lower bounds on the likely size of any true effect.

- Bias must be assessed before confidence intervals can be interpreted. Even very large samples and very narrow confidence intervals can mislead if they come from biased studies.

\section{Interpretation of Effect size:}

Effect size for difference between means. Effect size is used to measure the magnitude of a treatment effect. The used effect size estimate is Cohen's d. Cohen's d is computed by dividing the mean difference between groups by the pooled standard deviation.

\begin{tabular}{|c|c|c|}
\hline \multicolumn{3}{|c|}{$\begin{array}{l}\text { Cohen's Benchmarks } \\
\text { •Jacob Cohen (1988) proposed general definitions for } \\
\text { interpreting effect size estimates: }\end{array}$} \\
\hline & Cohen's d & $\mathbf{R}$ \\
\hline Small & \pm 0.20 & 0.10 \\
\hline Medium & \pm 0.50 & 0.30 \\
\hline Large & \pm 0.8 and above & 0.50 \\
\hline
\end{tabular}

Accordingly, an effect size of 0.0 indicates that the treatment mean is located at the 50th percentile of the control group distribution; an effect size of 0.8 would place the treatment group mean at the 79th percentile of the control group; and an effect size of 1.7 means that the mean of the treated group is positioned at about the 95th percentile of the control group.

Table 1: Basic Characteristics of the subjects studied

\begin{tabular}{|c|c|c|c|c|c|c|}
\hline \multicolumn{2}{|c|}{ Basic Characteristics of the subjects studied } & \multicolumn{2}{|c|}{ Study Group } & \multicolumn{2}{|c|}{ Control Group } & Between the groups Significance \\
\hline \multicolumn{2}{|c|}{ Number of subjects studied (n) } & \multicolumn{2}{|c|}{20} & \multicolumn{2}{|c|}{20} & -- \\
\hline \multicolumn{2}{|c|}{ Age in years (Mean \pm SD) } & \multicolumn{2}{|c|}{$26.25 \pm 5.07(21-37)$} & \multicolumn{2}{|c|}{$23.05 \pm 2.58(20-29)$} & $\mathrm{p}=0.158(\mathrm{NS})$ \\
\hline \multicolumn{2}{|c|}{ Duration in month } & \multicolumn{2}{|c|}{$14.85 \pm 7.92(6-36)$} & \multicolumn{2}{|c|}{$11.45 \pm 6.29(6-36)$} & $\mathrm{p}=0.637(\mathrm{NS})$ \\
\hline \multirow[t]{2}{*}{ Gender } & Males & 04 & $20 \%$ & 04 & $20 \%$ & \multirow[t]{2}{*}{--} \\
\hline & Females & 16 & $80 \%$ & 16 & $80 \%$ & \\
\hline Side & Right & 13 & $65 \%$ & 8 & $40 \%$ & \\
\hline
\end{tabular}

The above table shows that in study Group there were 20 subjects with mean age 26.25 years and there were 04 males and 16 females were included in the study. In Control Group there were 20 subjects with mean age 23.05 years and there were 04 males and 16 females were included in the study. There is no significant difference in mean ages between the groups.

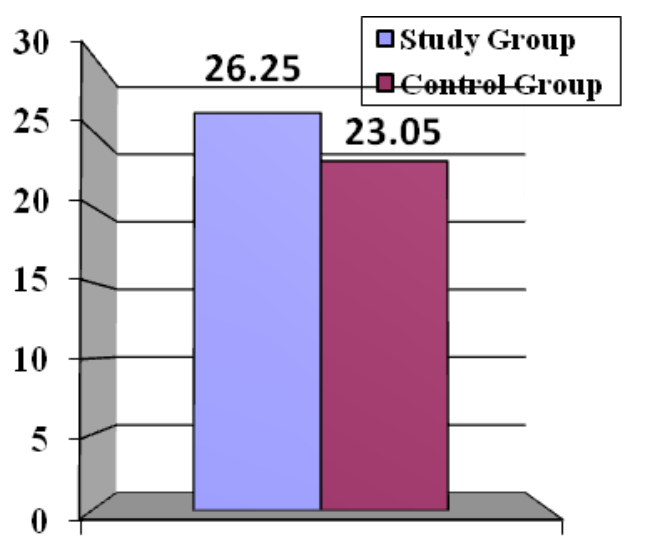

Age in years

Graph 1: Age Distribution of the subjects studied

The above graph shows that that in study Group there were 20 subjects with 
Kalpana et.al. Effect of agility and perturbation training on pain, balance and functional ability in subjects with patellofemoral pain syndrome.

mean age 26.25 years and in Control Group there were 20 subjects with mean age 23.05 years

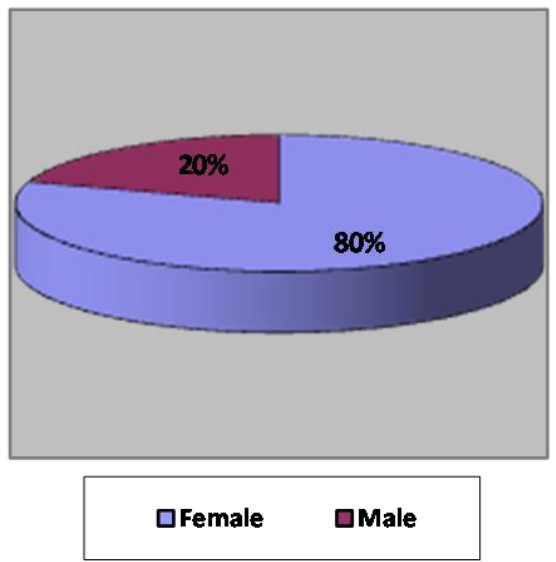

Graph 2: Gender distribution of the subjects in Study Group

The above graph shows that $80 \%$ of females and $20 \%$ of males were studied in study Group.

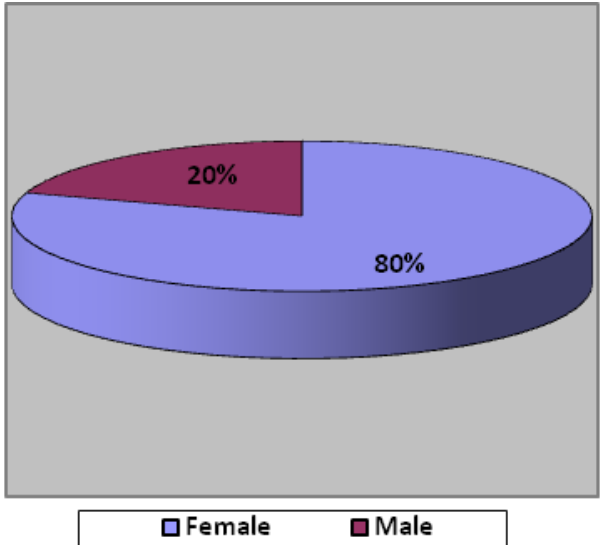

Graph 3: Gender distribution of the subjects Control Group

The above graph shows that $80 \%$ of females and $20 \%$ of males were studied in control Group.

\begin{tabular}{|c|c|c|c|c|c|c|c|}
\hline & \multirow{2}{*}{$\begin{array}{l}\text { Pre } \\
\text { intervention } \\
(\text { Mean } \pm \text { SD) } \\
\text { min-max }\end{array}$} & \multirow{2}{*}{$\begin{array}{l}\text { Post } \\
\text { intervention } \\
(\text { Mean } \pm \text { SD) } \\
\text { min-max }\end{array}$} & \multirow[t]{2}{*}{$\begin{array}{l}\text { Percentage } \\
\text { change }\end{array}$} & \multirow[t]{2}{*}{$\begin{array}{l}\text { Z value } \\
\text { ( Non parametric }^{\text {significance) }}\end{array}$} & \multirow[t]{2}{*}{$\begin{array}{l}\text { t value } \\
\text { (parametric } \\
\text { significance) }\end{array}$} & \multicolumn{2}{|c|}{$\begin{array}{l}95 \% \text { Confidence } \\
\text { interval of the } \\
\text { difference }\end{array}$} \\
\hline & & & & & & Lower & Upper \\
\hline & \multicolumn{5}{|l|}{ Study Group } & & \\
\hline NPRS & $\begin{array}{c}5.90 \pm .718 \\
(5-7)\end{array}$ & $\begin{array}{c}1.80 \pm .616 \\
(1-3)\end{array}$ & $-69.49 \%$ & $\begin{array}{c}-4.030 \\
\mathrm{P}<0.000^{* *}\end{array}$ & $\begin{array}{c}28.617 \\
\mathrm{P}<0.000^{* *}\end{array}$ & 3.800 & 4.400 \\
\hline $\begin{array}{l}\text { Composite } \\
\text { score YBT- } \\
\text { RIGHT }\end{array}$ & $\begin{array}{c}79.35 \pm 6.50 \\
(67-92)\end{array}$ & $\begin{array}{c}83.79 \pm 5.94 \\
(72-96)\end{array}$ & $5.38 \%$ & $\begin{array}{c}-3.921 \\
\mathrm{P}<0.000 * *\end{array}$ & $\begin{array}{c}-15.305 \\
\mathrm{P}<0.000^{* *}\end{array}$ & -5.053 & -3.838 \\
\hline $\begin{array}{l}\text { Composite } \\
\text { score YBT- } \\
\text { LEFT }\end{array}$ & $\begin{array}{c}80.86 \pm 6.97 \\
(68-95)\end{array}$ & $\begin{array}{c}86.01 \pm 1.41 \\
(75-97)\end{array}$ & $6.36 \%$ & $\begin{array}{c}-3.920 \\
\mathrm{P}<0.000 * *\end{array}$ & $\begin{array}{c}-13.606 \\
\mathrm{P}<0.000^{* *}\end{array}$ & -5.947 & -4.361 \\
\hline Kujala score & $\begin{array}{c}74.15 \pm 5.09 \\
(65-84)\end{array}$ & $\begin{array}{c}88.15 \pm 2.39 \\
(84-93)\end{array}$ & $18.88 \%$ & $\begin{array}{c}-3.929 \\
\mathrm{P}<0.000 * *\end{array}$ & $\begin{array}{c}-14.505 \\
\mathrm{P}<0.000^{* *}\end{array}$ & -16.020 & -11.980 \\
\hline
\end{tabular}

The above table shows that in study group there is a statistically significant change in means of NPRS, Composite score YBT- right and left and Kujala score when means were analyzed from pre intervention to post intervention within the groups with $\mathrm{p}<0.000$ with positive percentage of change showing that there is increase in the post means following intervention and with negative percentage showing there is decreasing in post means.

Table 3: Analysis of NPRS, YBT and Kujala score within Control Group (Pre to post test analysis)

\begin{tabular}{|c|c|c|c|c|c|c|c|}
\hline & \multirow{2}{*}{$\begin{array}{l}\text { Pre } \\
\text { intervention } \\
(\text { Mean } \pm \text { SD) } \\
\text { min-max } \\
\end{array}$} & \multirow{2}{*}{$\begin{array}{l}\text { Post } \\
\text { intervention } \\
(\text { Mean } \pm \text { SD) } \\
\text { min-max }\end{array}$} & \multirow[t]{2}{*}{$\begin{array}{l}\text { Percentage } \\
\text { change }\end{array}$} & \multirow[t]{2}{*}{$\begin{array}{l}\mathrm{Z} \text { value } \\
\text { (Non parametric }^{\text {(Nignificance) }}{ }^{\mathrm{a}}\end{array}$} & \multirow[t]{2}{*}{$\begin{array}{l}\text { value } \\
\text { (parametric }_{\text {significance) }}\end{array}$} & \multicolumn{2}{|c|}{\begin{tabular}{ll}
$95 \%$ & \multicolumn{2}{c}{ Confidence } \\
interval of the \\
difference
\end{tabular}} \\
\hline & & & & & & Lower & Upper \\
\hline & \multicolumn{5}{|c|}{ Control Group } & & \\
\hline NPRS & $\begin{array}{l}4.95 \pm 0.75 \\
\quad(4-6)\end{array}$ & $\begin{array}{c}2.15 \pm 0.98 \\
(1-5)\end{array}$ & $-56.57 \%$ & $\begin{array}{c}-4.117 \\
\mathrm{P}<0.000^{* *}\end{array}$ & $\begin{array}{c}16.310 \\
\mathrm{P}<0.000^{* *}\end{array}$ & 2.441 & 3.159 \\
\hline $\begin{array}{l}\text { Composite score } \\
\text { YBT- RIGHT }\end{array}$ & $\begin{array}{c}89.40 \pm 5.62 \\
(74-96) \\
\end{array}$ & $\begin{array}{c}93.07 \pm 5.66 \\
(77-99) \\
\end{array}$ & $4.10 \%$ & $\begin{array}{c}-3.920 \\
\mathrm{P}<0.000^{* *}\end{array}$ & $\begin{array}{c}-18.083 \\
\mathrm{P}<0.000^{* *} \\
\end{array}$ & -4.096 & -3.247 \\
\hline $\begin{array}{l}\text { Composite score } \\
\text { YBT-LEFT }\end{array}$ & $\begin{array}{c}88.93 \pm 6.34 \\
(71-95)\end{array}$ & $\begin{array}{c}92.85 \pm 6.15 \\
(74-99)\end{array}$ & $4.40 \%$ & $\begin{array}{c}-3.920 \\
\mathrm{P}<0.000^{* *}\end{array}$ & $\begin{array}{c}-12.206 \\
\mathrm{P}<0.000^{* *}\end{array}$ & -4.588 & -3.244 \\
\hline Kujala score & $\begin{array}{c}77.85 \pm 4.08 \\
(72-84)\end{array}$ & $\begin{array}{c}88.48 \pm 3.10 \\
(82-95)\end{array}$ & $13.65 \%$ & $\begin{array}{c}-3.925 \\
\mathrm{P}<0.000^{* *}\end{array}$ & $\begin{array}{c}-13.926 \\
\mathrm{P}<0.000^{* *}\end{array}$ & -12.596 & -9.304 \\
\hline
\end{tabular}

** Statistically Significant difference $p<0.05 ;$ NS- Not significant; a. Wilcoxon Signed Ranks Test, $b$. Paired t test 

patellofemoral pain syndrome.

The above table shows that in control group there is a statistically significant change in means of NPRS, Composite score YBT- right and left and Kujala score when means were analyzed from pre intervention to post intervention within the groups with $p<0.000$ with positive percentage of change showing that there is increase in the post means following intervention and with negative percentage showing there is decreasing in post means.

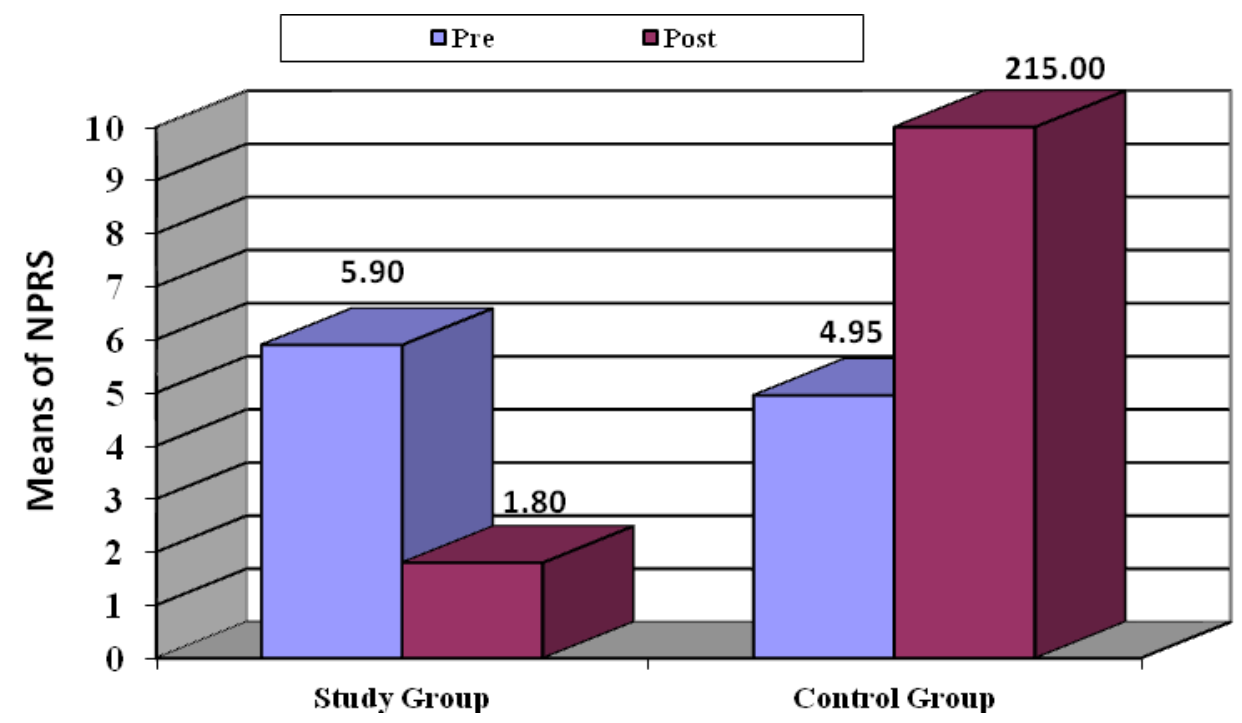

Graph- 4: Analysis of NPRS within study and control Groups (Pre to post test analysis)

The above graph shows that in both groups there is a statistically significant change in means of NPRS score when means were analyzed from pre intervention to post intervention within the groups with $\mathrm{p}<0.000$.

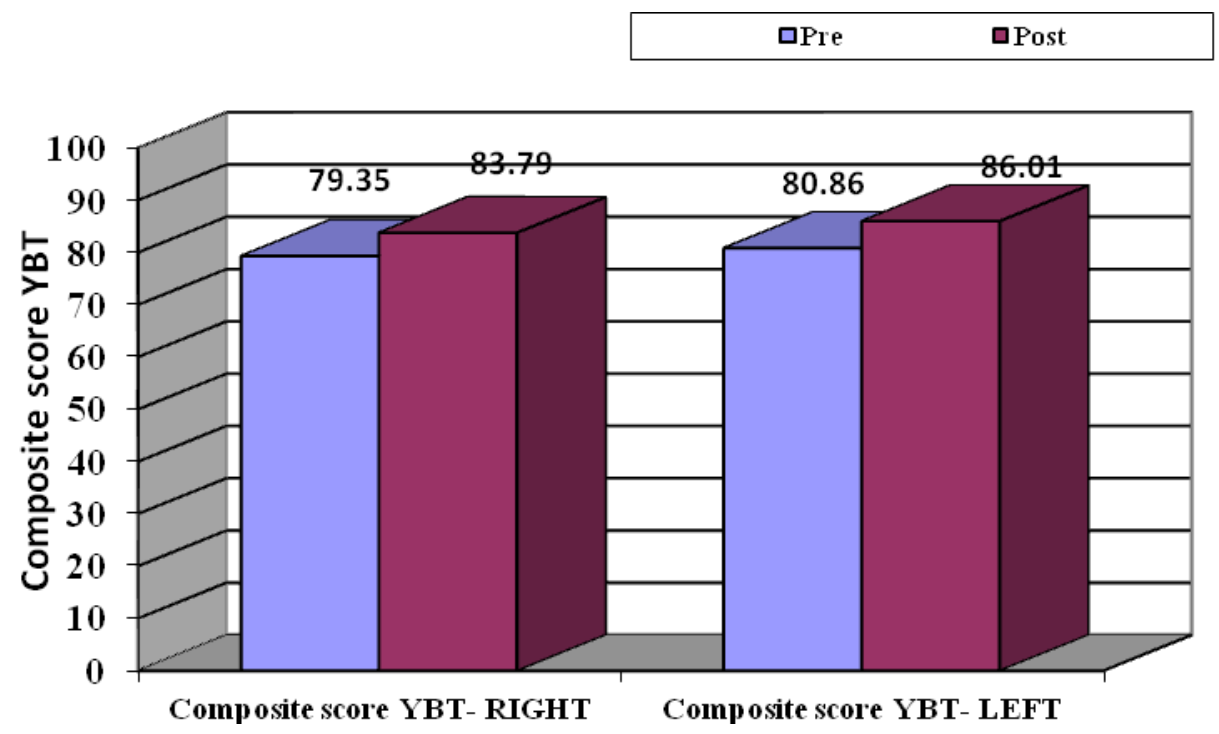

Graph- 5: Analysis of Composite score YBT within study Group (Pre to post test analysis)

The above graph shows that in study groups there is a statistically significant change in means of NPRS score when means were analyzed from pre intervention to post intervention within the groups with $\mathrm{p}<0.000$. 
Kalpana et.al. Effect of agility and perturbation training on pain, balance and functional ability in subjects with patellofemoral pain syndrome.

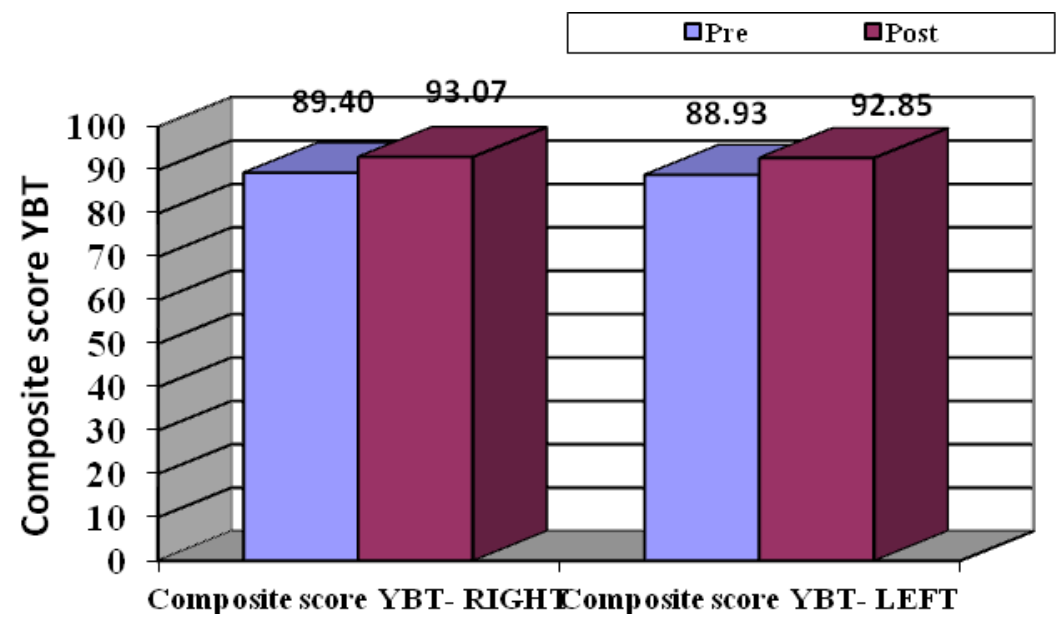

Graph- 6: Analysis of Composite score YBT within control Group (Pre to post test analysis)

The above graph shows that in control groups there is a statistically significant change in means of NPRS score when means were analyzed from pre intervention to post intervention within the groups with $\mathrm{p}<0.000$.

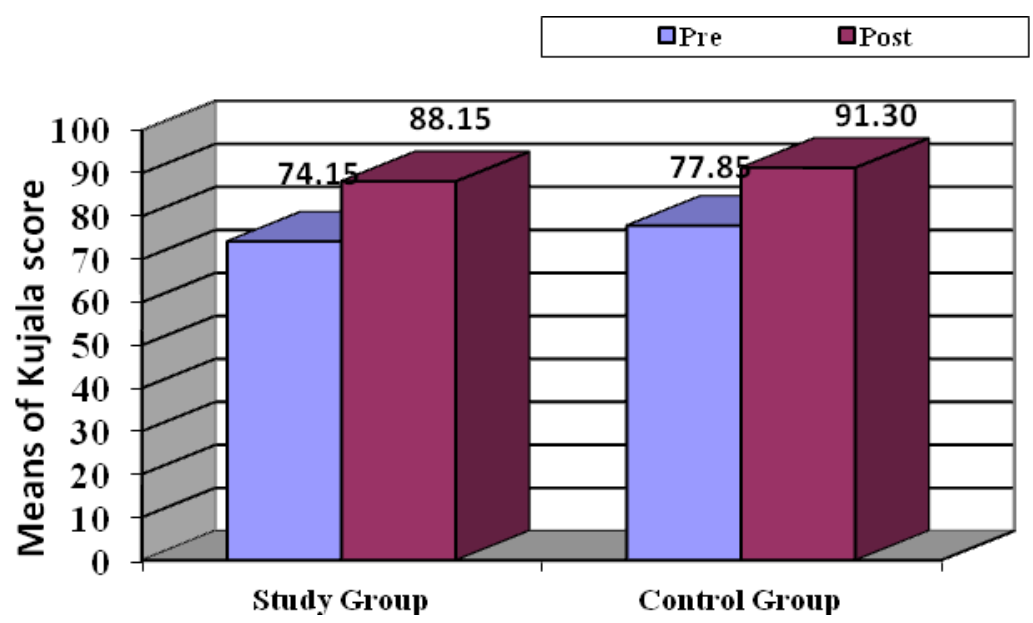

Graph- 7: Analysis of Kujala Score within Groups (Pre to post test analysis)

Table 4: Comparison of means of NPRS and Kujala score between Groups (PRE AND POST TEST COMPARISION)

\begin{tabular}{|c|c|c|c|c|c|c|c|}
\hline & \multirow{2}{*}{$\begin{array}{l}\text { Study } \\
\text { Group } \\
(\text { Mean } \pm \text { SD) } \\
\text { min-max }\end{array}$} & \multirow[t]{2}{*}{$\begin{array}{l}\text { Control Group } \\
\text { (Mean } \pm \text { SD) } \\
\text { min-max }\end{array}$} & \multirow[t]{2}{*}{$\begin{array}{l}\text { Percentage of } \\
\text { difference }\end{array}$} & \multirow[t]{2}{*}{$\begin{array}{l}Z \text { value }{ }^{\mathrm{b}} \text { ( Non } \\
\text { parametric) }\end{array}$} & \multirow[t]{2}{*}{$\begin{array}{l}\text { t value } \\
\text { (parametric } \text { significance) }^{\mathrm{a}}\end{array}$} & \multicolumn{2}{|c|}{$\begin{array}{l}95 \% \text { Confidence } \\
\text { interval of the } \\
\text { difference }\end{array}$} \\
\hline & & & & & & Lower & Upper \\
\hline \multicolumn{8}{|c|}{ PRE } \\
\hline NPRS & $\begin{array}{c}5.90 \pm .718 \\
(5-7)\end{array}$ & $\begin{array}{c}1.80 \pm .616 \\
(1-3)\end{array}$ & $-1.06 \%$ & $\begin{array}{c}\mathrm{Z}=-3.382 \\
\mathrm{P}<0.001^{* *}\end{array}$ & $\begin{array}{c}4.065 \\
\mathrm{P}<0.000^{* *}\end{array}$ & 0.477 & 1.423 \\
\hline $\begin{array}{l}\text { Composite score } \\
\text { YBT- RIGHT }\end{array}$ & $\begin{array}{c}79.35 \pm 6.50 \\
(67-92)\end{array}$ & $\begin{array}{c}83.79 \pm 5.94(72 \\
-96)\end{array}$ & $5.43 \%$ & $\begin{array}{l}\mathrm{Z}=-4.085 \\
\mathrm{P}<0.000^{* *}\end{array}$ & $\begin{array}{c}-5.230 \\
\mathrm{P}<0.000^{* *}\end{array}$ & -13.947 & -6.163 \\
\hline $\begin{array}{l}\text { Composite score } \\
\text { YBT-LEFT }\end{array}$ & $\begin{array}{c}80.86 \pm 6.97 \\
(68-95)\end{array}$ & $\begin{array}{c}86.01 \pm 1.41 \\
(75-97) \\
\end{array}$ & $6.17 \%$ & $\begin{array}{c}\mathrm{Z}=-3.517 \\
\mathrm{P}<0.000 * *\end{array}$ & $\begin{aligned} & -3.829 \\
\mathrm{P} & <0.000 * *\end{aligned}$ & -12.342 & -3.805 \\
\hline Kujala score & $\begin{array}{c}74.15 \pm 5.09 \\
(65-84)\end{array}$ & $\begin{array}{c}77.85 \pm 4.08 \\
(72-84)\end{array}$ & $4.86 \%$ & $\begin{array}{c}\mathrm{Z}=-2.133 \\
\mathrm{P}<0.033^{* *}\end{array}$ & $\begin{aligned} &-2.536 \\
& \mathrm{P}<0.015 * *\end{aligned}$ & -6.654 & -.746 \\
\hline \multicolumn{8}{|c|}{ POST } \\
\hline NPRS & $\begin{array}{c}1.80 \pm .616 \\
(1-3)\end{array}$ & $\begin{array}{c}2.15 \pm 0.98 \\
(1-5)\end{array}$ & $17.94 \%$ & $\begin{array}{c}\mathrm{Z}=-1.129 \\
\mathrm{P}=0.259(\mathrm{NS})\end{array}$ & $\begin{aligned} & -1.345 \\
\mathrm{P}= & 0.187(\mathrm{NS})\end{aligned}$ & -0.877 & 0.177 \\
\hline $\begin{array}{l}\text { Composite score } \\
\text { YBT- RIGHT }\end{array}$ & $\begin{array}{c}83.79 \pm 5.94 \\
(72-96) \\
\end{array}$ & $\begin{array}{c}93.07 \pm 5.66(77 \\
-99)\end{array}$ & $10.49 \%$ & $\begin{array}{c}\mathrm{Z}=-4.004 \\
\mathrm{P}<0.000 * *\end{array}$ & $\begin{array}{c}-5.053 \\
\mathrm{P}<0.000^{* *}\end{array}$ & -12.999 & -5.563 \\
\hline $\begin{array}{l}\text { Composite score } \\
\text { YBT-LEFT }\end{array}$ & $\begin{array}{c}86.01 \pm 1.41 \\
(75-97)\end{array}$ & $\begin{array}{c}92.85 \pm 6.15 \\
(74-99)\end{array}$ & $7.64 \%$ & $\begin{array}{c}\mathrm{Z}=-3.381 \\
\mathrm{P}<0.000 * *\end{array}$ & $\begin{aligned} &-3.466 \\
& \mathrm{P}<0.001 * *\end{aligned}$ & -10.828 & -2.843 \\
\hline Kujala score & $\begin{array}{c}88.15 \pm 2.39 \\
(84-93)\end{array}$ & $\begin{array}{c}88.48 \pm 3.10 \\
(82-95)\end{array}$ & $0.373 \%$ & $\begin{array}{c}\mathrm{Z}=-.916 \\
\mathrm{P}=0.360(\mathrm{NS})\end{array}$ & $\begin{array}{c}-.742 \\
\mathrm{P}=0.463(\mathrm{NS})\end{array}$ & -2.424 & 1.124 \\
\hline
\end{tabular}

** Statistically Significant difference $p<0.05 ;$ NS- Not significant $\quad a$. Independent $t$ test $b$. Mann-Whitney Test 

patellofemoral pain syndrome.

The above graph shows that in both Groups there is a statistically significant change in means of Kujala score when means were analyzed from pre intervention to post intervention within the groups with $\mathrm{p}<0.000$.

The above table shows that when pre intervention means of NPRS, Composite score YBT and Kujala Score were compared there is a statistically significant difference between the groups. When post intervention means of NPRS and Kujala score were compared between the groups there is no statistically significant difference between the groups. When post intervention means of Composite score YBT were compared there is a statically significant difference.

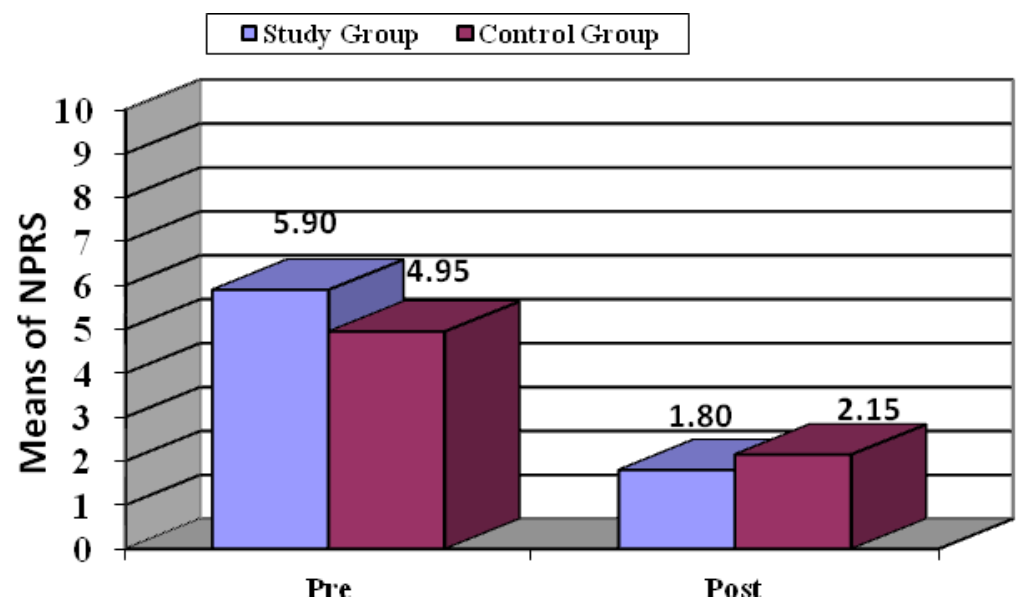

Graph- 8: Analysis of NPRS between study and control Groups (Pre to pre and post to post test analysis)

The above graph shows that in both groups there is a statistically significant change in means of NPRS score when pre intervention means were analyzed between the groups with $\mathrm{p}<0.000$. Whereas there is no statistically significant difference in post intervention between the groups.

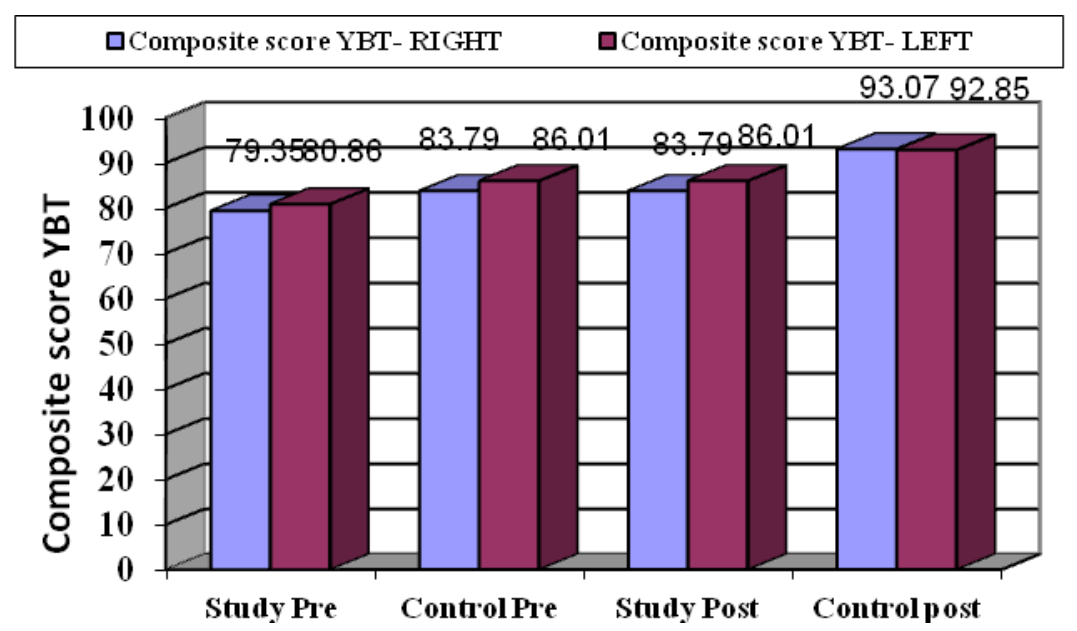

Graph- 9: Analysis of Composite score YBT between the Groups (Pre to post test analysis)

The above graph shows that between the groups analysis found that there is a statistically significant difference in means of right and left YBT score when means were analyzed between the groups with $\mathrm{p}<0.000$. 


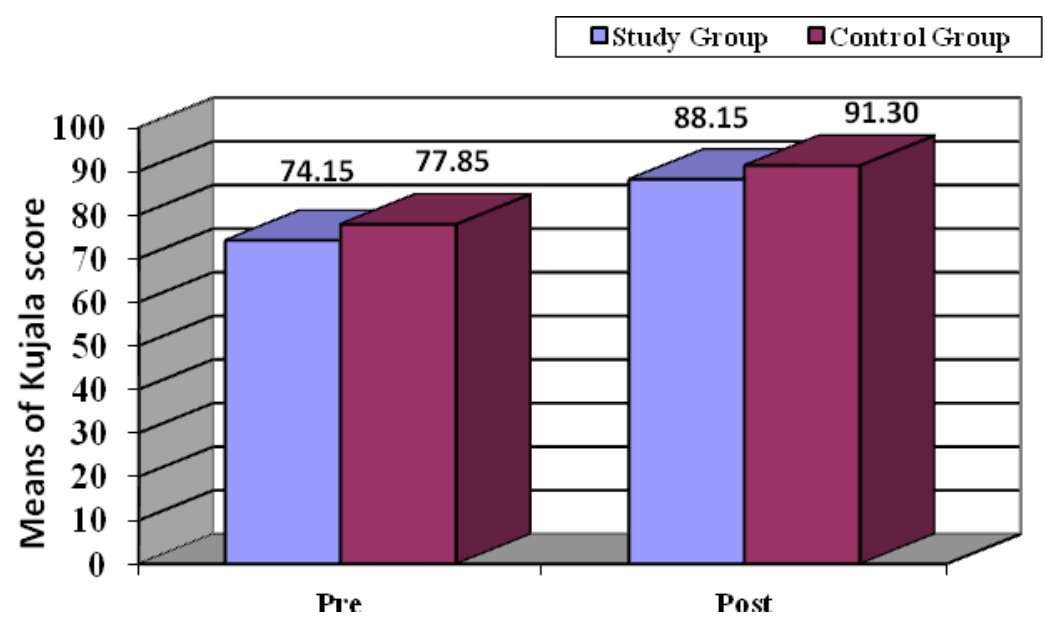

Graph- 10: Analysis of Kujala Score between the Groups (Pre to post test analysis)

The above graph shows that in both groups there is a statistically significant change in means of Kujala score when pre intervention means were analyzed between the groups with $\mathrm{p}<0.000$. Whereas there is no statistically significant difference in post intervention between the groups.

\section{DISCUSSION}

In the present study it is found that following 4 weeks of intervention of agility, perturbation with conventional exercises there is a statistically significant improvement in pain measured using NPRS, balance measured using of Composite score YBT- right and left, and function measured using Kujala score in subjects with patellofemoral pain syndrome. It is also found that there is a statistically significant improvement in pain, balance, and function ability in subjects who received conventional exercises. When post intervention means of NPRS and Kujala score were compared between the groups there is no statistically significant difference between the groups. When post intervention means of Composite score YBT were compared there is a statically significant difference. There is a statistical greater improvement shown in study group.

\section{Study group}

There is a statistically significant improvement in pain in both the groups by means of NPRS when means were analyzed from pre intervention to post intervention within the groups.

Quadriceps strengthening plays an important role in the management of patellofemoral pain syndrome. Aim of the exercises is to improve patellar tracking, decrease retinacular strain, and decrease patellofemoral joint stress. Laura kookier et al., conducted a study on "Effects of Physical Therapist-Guided QuadricepsStrengthening Exercises" for the Treatment of Patellofemoral Pain Syndrome and he found that quadriceps strengthening exercises can reduce patellofemoral pain. ${ }^{31}$

In addition to the exercises Agility and Perturbation also plays an important role in management of patellofemoral pain syndrome. The intent of agility and perturbation training activities is to expose people to activities that challenge knee stability and balance in a controlled manner during rehabilitation, a strategy that may allow them to develop motor skills adequate to protect the knee from potentially harmful loads during functional activities. ${ }^{1}$

During open chain exercises, the amount of quadriceps muscle force required to extend the knee progressively increases as the knee moves from $90^{\circ}$ to full knee extension. As well, the patellofemoral joint contact area diminishes as the knee extends, thereby increasing patellofemoral joint stress. By contrast, during closed chain exercises the quadriceps muscle force is minimal at full knee extension and 
therefore, patellofemoral joint stresses are reduced. ${ }^{6}$

Several authors discussed possible explanations for the effectiveness of exercise programs in relieving pain in patients with PFPS. Most studies associated the increase in functional muscle strength, altered sensorimotor behavior, and the restoration of patella alignment with a reduction of stress on the patellofemoral joint. The improvements of motor control motion and patellofemoral joint performance appear to be important factors in the management of patellofemoral pain syndrome.

There is a statistically significant improvement of function in both the groups. The Kujala PFPS scale assesses the pain, function and limitation of joint motion. Robinson et al. found mean values to be 69.7 in patients and did not record control groups' values. Crossley et al., noted that improvement of patients' Kujala scores in the treatment group was more likely than in the placebo group. In the current study scores increases in both the group. We found better Kujala score in study group with the mean value of $88.15 \pm 2.39$ after treatment and before treatment mean value was $74.15 \pm 5.09$.

Agility and perturbation training helps patients to develop motor skills adequate to protect their knees from potentially harmful loads while increasing their physical performance capabilities. ${ }^{45}$

This result indicates that exercise decrease pain and increase function in patients suffering from PFPS. However, the magnitude of effect for the improvements in pain and function in patients receiving exercise therapy were considerably higher and represent a favorable treatment for patients suffering from PFPS. ${ }^{34}$

G Kelley Fitzgerald et al., found that rehabilitation with agility and perturbation training program may assist the patient in returning to higher levels of physical activity with less pain and instability following rehabilitation. ${ }^{17}$ Hayri Baran Yosmaoglu et al., conclude functional movement depends not only on the acquisition of stimuli from peripheral mechanoreceptors in joints, muscles, and deep tissues but also on the regulation of this motion via agonist-antagonist muscle activation by the central nervous system. In addition to strength, accurate motor control requires multimodal central nervous system activation associated with merging afferent information and central representation. ${ }^{12}$ There is a statistically significant improvement of balance in both the groups. In the study group there is a significant improvement in balance due to agility and perturbation training.

Devrimakeski et al., found in their study that proprioceptive quality decreased in PFPS. Proprioceptive changes should also be considered in the etiology of the disorder besides the mechanical and biochemical factors. The presence of proprioceptive deficiency in PFPS may be due to abnormal forces at the surrounding tissues which already go along with the disorder may deteriorate the proprioception by affecting the motor control. Pain and inflammation may also contribute to proprioceptive deficiency.

The dynamic stability of the body, or any specific joint such as the knee, is contingent on neuromuscular control of the displacement of all contributing body segments during movement. According to Zazulak et al. (2007), a deficit of neuromuscular control in the trunk can compromise the dynamic stability of the knee and lead to joint damage. Therefore, neuromuscular training, involving proprioceptive exercises related to disturbance and the correction of body sway, are indicated. ${ }^{18}$ Although there is limited understanding of the neuromuscular control mechanisms that play a role in maintaining knee stability. Johansson and Sjo"lander have suggested that stimulation of mechanoreceptors in joint structures increases gamma motor activity in a manner that may increase the sensitivity of muscle spindles in muscles associated with the joint. This increased sensitivity of the 
muscle spindles may result in a higher state of "readiness" of muscles to respond to perturbing forces applied to the joint, which may, in turn, improve joint stability.

The afferent mechanism in this response appears to respond to moderate levels of force and theoretically could be activated during perturbations that occur during functional activity. The implication for treatment may be that applying potentially destabilizing forces to the knee during treatment may enhance neuromuscular responses to destabilizing forces that may be encountered during function. Nichols proposed a "forcefeedback" hypothesis, explained the coordinated response from muscles to perturbing forces applied to a joint. When a perturbing force is applied to a joint, muscles that would resist the perturbation are stretched and become activated to resist the perturbation. Simultaneously, there is a reflex inhibitory influence on muscles that would have a tendency to pull in the same direction as the perturbation. The inhibitory influence reduces, but does not entirely eliminate, the unwanted stretch reflex from muscles antagonistic to those that would resist the perturbing force. The net result is a coordinated co activation of extremity muscles affected by the perturbation to stiffen the joint and maintain stability. ${ }^{46}$

\section{Control group}

Similarly there is improvement in control group improvement would be due to strengthening exercise. Cynthia la bella concluded in her study that exercises helps to improve proprioception and proprioceptive input contributes to the neuromuscular control of patellar tracking. ${ }^{9}$

\section{Comparison between both groups}

In this study when pre intervention means of NPRS, Composite score YBT and Kujala Score were compared there is a statistically significant difference between the groups. When post intervention means of NPRS and Kujala score were compared between the groups there is no statistically significant difference between the groups. When post intervention means of Composite score YBT were compared there is a statically significant difference.

Exercise programs based on strengthening the quadriceps have been shown to decrease pain and improve motor

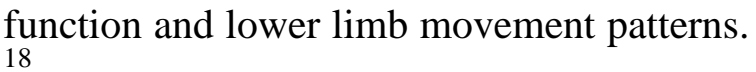

Based on the analysis, this study found that there is a significant difference in composite YBT score between the groups.

\section{LIMITATIONS OF THE STUDY:}

1. The study was conducted on small samples.

2. It's difficult to determine the long-term effect on outcome measures as intervention was done only for four weeks.

3. Pain, balance and functional ability were measured but affect on muscle strength, co-ordination, were not measured.

4. The factors that references on pain and functional ability such as lifestyle activities, obesity, severity of PFP, duration of PFP were not considered.

\section{CONCLUSION}

The present study concluded that four weeks Agility and Perturbation training along with conventional exercises and conventional exercises both shown significant effect on improvement of pain, balance and functional abilities in subject with patellofemoral pain syndrome. When the effect of improvement obtained following agility and perturbation with conventional exercises shows significant different in balance improvement compared to conventional exercises but there is no difference in improvement of pain and functional ability.

Hence agility and perturbation training found to have effect on improvement of balance compared to conventional exercises.

It is recommended clinically that to consider Agility and Perturbation training shows improvement in pain, balance and 
Kalpana et.al. Effect of agility and perturbation training on pain, balance and functional ability in subjects with patellofemoral pain syndrome.

functional abilities in subject with Patellofemoral pain syndrome.

\section{Recommendation For Future Research}

1. Further Study should be conducted on large sample to see affect.

2. It's recommended to increase the Intervention time to get the long term affect.

3. Further study needed to find the effect of agility and perturbation on improvement of strength, agility, coordination are needed.

\section{SUMMARY}

Agility and Perturbation both have been affirmed to show improvement of pain, balance and functional abilities in subject with Patellofemoral pain syndrome. The purpose of the study is to find effect of agility and perturbation training on improvement of pain, balance and functional abilities in subject with Patellofemoral pain syndrome.

A Randomized experimental study design, 40 individuals with patellofemoral pain was selected. 20 subjects in study group and 20 subjects in control group. NPRS, YBT, Kujala scale were measured before and after the treatment.

Analysis using Mann Whitney ' $U$ ' Test and Independent ' $t$ ' test found that when pre intervention means of NPRS, Composite score YBT and Kujala Score were compared there is a statistically significant difference between the groups. When post intervention means of NPRS and Kujala score were compared between the groups there is no statistically significant difference between the groups. When post intervention means of Composite score YBT were compared there is a statically significant difference.

Conflict of Interest: The authors declare no conflicts of interest with respect to the authorship and/or publication of this article.

Ethical Approval: Approved.

\begin{tabular}{|c|c|c|}
\hline \multicolumn{3}{|c|}{ List of Abbreviations } \\
\hline PFPS & : & Patellofemoral pain syndrome \\
\hline NPRS & : & Numeric pain rating scale \\
\hline BMI & & Body mass index \\
\hline $\mathbf{A R}$ & & Anterior reach \\
\hline PMR & & Posteromedial reach \\
\hline PLR & & Posterolateral reach \\
\hline YBT & & Y balance test \\
\hline
\end{tabular}

Acknowledgement: None

\section{Source of Funding: None}

\section{REFERENCES}

1. Earl JE, Hoch AZ. A proximal strengthening program improves pain, function, and biomechanics in women with patellofemoral pain syndrome. The American journal of sports medicine. 2011 Jan;39(1):154-63.

2. Roush JR, Bay RC. Prevalence of anterior knee pain in 18-35 year-old females. International journal of sports physical therapy. 2012 Aug;7(4):396.

3. Boling M, Padua D, Marshall S, Guskiewicz K, Pyne S, Beutler A. Gender differences in the incidence and prevalence of patellofemoral pain syndrome. Scandinavian journal of medicine \& science in sports. 2010 Oct 1;20(5):725-30.

4. Witvrouw E, Werner S, Mikkelsen C, Van Tiggelen D, Berghe LV, Cerulli G. Clinical classification of patellofemoral pain syndrome: guidelines for non-operative treatment. Knee Surgery, Sports Traumatology, Arthroscopy. 2005 Mar 1;13(2):122-30.

5. Petersen W, Ellermann A, GöseleKoppenburg A, Best R, Rembitzki IV, Brüggemann GP, Liebau C. Patellofemoral pain syndrome. Knee surgery, sports traumatology, and arthroscopy. 2014 Oct 1;22(10):2264-74.

6. Halabchi F, Mazaheri R, Seif-Barghi T. Patellofemoral pain syndrome and modifiable intrinsic risk factors; how to assess and address? Asian journal of sports medicine. 2013 Jun; 4(2):85.

7. Dixit S, Difiori JP, Burton M, Mines B. Management of patellofemoral pain syndrome. Am Fam Physician. 2007 Jan 15; 75(2):194-202. 
8. Powers CM. Patellar kinematics, part I: the influence of vastus muscle activity in subjects with and without patellofemoral pain. Physical therapy. 2000 Oct 1;80(10):956-64.

9. LaBella C. Patellofemoral pain syndrome: evaluation and treatment. Primary Care: Clinics in Office Practice. 2004 Dec 1;31(4):977-1003.

10. Baker V, Bennell K, Stillman B, Cowan S, Crossley K. Abnormal knee joint position sense in individuals with patellofemoral pain syndrome. Journal of Orthopaedic Research. 2002 Mar 1;20(2):208-14.

11. Akseki D, Akkaya G, Erduran M, Pinar H. Proprioception of the knee joint in patellofemoral pain syndrome. ActaOrthop TraumatolTurc. 2008 Nov 1;42(5):316-21.

12. Yosmaoglu HB, Kaya D, Guney H, Nyland J, Baltaci G, Yuksel I, Doral MN. Is there a relationship between tracking ability, joint position sense, and functional level in patellofemoral pain syndrome? Knee Surgery, Sports Traumatology, Arthroscopy. 2013 Nov 1;21(11):2564-71.

13. Crossley K, Bennell K, Green S, Cowan S, McConnell J. Physical therapy for patellofemoral pain: a randomized, doubleblinded, placebo-controlled trial. The American journal of sports medicine. 2002 Nov;30(6):857-65.

14. Callaghan MJ, Selfe J, Bagley PJ, Oldham JA. The effects of patellar taping on knee joint proprioception. Journal of athletic training. 2002 Jan;37(1):19.

15. Devereaux MD, Lachmann SM. Patellofemoral arthralgia in athletes attending a Sports Injury Clinic. British journal of sports medicine. 1984 Mar 1;18(1):18-21.

16. Sheppard JM, Young WB. Agility literature review: Classifications, training and testing. Journal of sports sciences. 2006 Sep 1;24(9):919-32.

17. Fitzgerald GK, Childs JD, Ridge TM, Irrgang JJ. Agility and perturbation training for a physically active individual with knee osteoarthritis. Physical therapy. 2002 Apr 1;82(4):372-82.

18. dos AnjosRabelo ND, Lima B, dos Reis AC, Bley AS, Yi LC, Fukuda TY, Costa LO, Lucareli PR. Neuromuscular training and muscle strengthening in patients with patellofemoral pain syndrome: a protocol of randomized controlled trial. BMC musculoskeletal disorders. 2014 Dec; 15(1):157.

19. Paterno MV, Myer GD, Ford KR, Hewett TE. Neuromuscular training improves single-limb stability in young female athletes. Journal of Orthopaedic\& Sports Physical Therapy. 2004 Jun;34(6):305-16.

20. Horak FB, Henry SM, Shumway-Cook A. Postural perturbations: new insights for treatment of balance disorders. Physical therapy. 1997 May 1;77(5):517-33.

21. Allum JH, Bloem BR, Carpenter MG, Hulliger M, Hadders-Algra M. Proprioceptive control of posture: a review of new concepts. Gait \& posture. 1998 Dec 1;8(3):214-42.

22. PatchavaApparao C, Swamy G, Subramaniam S. Effectiveness of Functional Task Exercises versus Agility and Perturbation Training in Osteoarthritis Knee Subjects. International Journal of Health Sciences and Research (IJHSR). 2015;5(9): 328-37.

23. Liporaci RF, Saad MC, Felício LR, Baffa AD, Grossi DB. Contribution of the evaluation of the clinical signals in patients with patellofemoral pain syndrome. Actaortopedicabrasileira. 2013 Aug;21(4):198-201.

24. Ittenbach RF, Huang G, Foss KD, Hewett TE, Myer GD. Reliability and validity of the anterior knee pain scale: Applications for use as an epidemiologic screener. PLOS one. 2016 Jul 21;11(7):e0159204.

25. Crossley KM, Bennell KL, Cowan SM, Green S. Analysis of outcome measures for persons with patellofemoral pain: which are reliable and valid? 1. Archives of physical medicine and rehabilitation. 2004 May $1 ; 85(5): 815-22$.

26. Johnson C. Measuring pain. Visual analog scale versus numeric pain scale: what is the difference? Journal of chiropractic medicine. 2005 Dec 1;4(1):43-4.

27. Lee DK, Kang MH, Lee TS, Oh JS. Relationships among the $\mathrm{Y}$ balance test, Berg Balance Scale, and lower limb strength in middle-aged and older females. Brazilian journal of physical therapy. 2015 Jun;19(3):227-34.

28. Shaffer SW, Teyhen DS, Lorenson CL, Warren RL, Koreerat CM, Straseske CA, Childs JD. Y-balance test: a reliability study involving multiple raters. Military medicine. 2013 Nov 1;178(11):1264-70. 
29. Lantz JM, Emerson-Kavchak AJ, Mischke JJ, Courtney CA. Tibiofemoral joint mobilization in the successful management of patellofemoral pain syndrome: a case report. International journal of sports physical therapy. $2016 \mathrm{Jun} ; 11(3): 450$.

30. Papadopoulos K, Noyes J, Jones JG, Thom JM, Stasinopoulos D. Clinical tests for differentiating between patients with and without patellofemoral pain syndrome. Hong Kong Physiotherapy Journal. 2014 Jun 1;32(1):35-43.

31. Kooiker L, Van De Port IG, Weir A, Moen MH. Effects of Physical Therapist-Guided Quadriceps-Strengthening Exercises for the Treatment of Patellofemoral Pain Syndrome: A Systematic Review. Journal of orthopaedic\& sports physical therapy. 2014 Jun;44(6):391-B1

32. .Arazpour M, Notarki TT, Salimi A, Bani MA, Nabavi H, Hutchins SW. The effect of patellofemoral bracing on walking in individuals with patellofemoral pain syndrome. Prosthetics and orthotics international. 2013 Dec;37(6):465-70.

33. Heintjes EM, Berger MY, Bierma-Zeinstra SM, Bernsen RM, Verhaar JA, Koes BW. Exercise therapy for patellofemoral pain syndrome. Cochrane Database Syst Rev. 2003 Jan 1;4.

34. Frye JL, Ramey LN, Hart JM. The effects of exercise on decreasing pain and increasing function in patients with patellofemoral pain syndrome: a systematic review. Sports health. 2012 May;4(3):205-10.

35. Kuru TU, Yalıman A, Dereli EE. Comparison of efficiency of Kinesio ${ }^{\circledR}$ taping and electrical stimulation in patients with patellofemoral pain syndrome. Actaorthopaedicaettraumatologicaturcica. 2012;46(5):385-92.

36. Harvie D, O'Leary T, Kumar S. A systematic review of randomized controlled trials on exercise parameters in the treatment of patellofemoral pain: what works?. Journal of multidisciplinary healthcare. 2011;4:383.

37. Ferber R, Kendall KD, Farr L. Changes in knee biomechanics after a hip-abductor strengthening protocol for runners with patellofemoral pain syndrome. Journal of athletic training. 2011 Mar;46(2):142-9.

38. Gharote GM, Shah SM, Yeole UL, Gawali PP, Adkitte RG. Evaluation of patellofemoral pain syndrome in national level weight lifters with anterior knee pain. Saudi Journal of Sports Medicine. 2016 Sep 1;16(3):192.

39. Glaviano NR, Kew M, Hart JM, Saliba S. Demographic and epidemiological trends in patellofemoral pain. International journal of sports physical therapy. $2015 \mathrm{Jun} ; 10(3): 281$.

40. Myer GD, Ford KR, Foss KD, Goodman A, Ceasar A, Rauh MJ, Divine JG, Hewett TE. The incidence and potential pathomechanics of patellofemoral pain in female athletes. Clinical biomechanics. 2010 Aug 1;25(7): 700-7.

41. Lankhorst NE, Bierma-Zeinstra SM, van Middelkoop M. Factors associated with patellofemoral pain syndrome: a systematic review. Br J Sports Med. 2013 Mar 1;47(4):193-206.

42. Waryasz GR, McDermott AY. Patellofemoral pain syndrome (PFPS): a systematic review of anatomy and potential risk factors. Dynamic medicine. 2008 Dec;7(1):9.

43. Shirazi ZR, Moghaddam MB, Motealleh A. Comparative evaluation of core muscle recruitment pattern in response to sudden external perturbations in patients with patellofemoral pain syndrome and healthy subjects. Archives of physical medicine and rehabilitation. 2014 Jul 1;95(7):1383-9.

44. Rhon D, Deyle G, Gill N, Rendeiro D. Manual physical therapy and perturbation exercises in knee osteoarthritis. Journal of Manual \& Manipulative Therapy. 2013 Nov 1;21(4):220-8.

45. Fitzgerald GK, Childs JD, Ridge TM, Irrgang JJ. Agility and perturbation training for a physically active individual with knee osteoarthritis. Physical therapy. 2002 Apr 1;82(4):372-82.

46. Fitzgerald GK, Axe MJ, Snyder-Mackler L. The efficacy of perturbation training in nonoperative anterior cruciate ligament rehabilitation programs for physically active individuals. Physical therapy. $2000 \mathrm{Feb}$ 1;80(2):128-40.

47. Shimwell L, Fatoye F, Selfe J. The Validity of the Modified Star Excursion Balance Test as a Predictor of Knee Extensor and Hip Abductor Strength. International Journal of Physiotherapy and Research. 2017 Feb 11;5(1):1863-71.

48. Alnahdi AH, Alderaa AA, Aldali AZ, Alsobayel $H$. Reference values for the $Y$ Balance Test and the lower extremity 
functional scale in young healthy adults. Journal of physical therapy science. 2015;27(12):3917-21.

49. Sakunkaruna S, Sakunkaruna Y, Sakulsriprasert P. Thai Version of the Kujala Patellofemoral Questionnaire in Knee Pain Patients: Cross-Cultural Validation and Test-Retest Reliability. Journal of the Medical Association of Thailand $=$ Chotmaihetthangphaet. 2015 Jun;98:S81-5.

50. Konstantinos. D. Papadopoulos, Dr Jeanette M Thom, Professor Jane Noyes, Jeremy G Jones and Dimitris Stasinopoulos .The reliability and meaningfulness of the anterior knee pain and lower extremity functional scales in patellofemoral pain syndrome .The Open Sports Science Journal. 2013; [6]: 26-30.

51. Piva SR, Gil AB, Moore CG, Fitzgerald GK. Responsiveness of the activities of daily living scale of the knee outcome survey and numeric pain rating scale in patients with patellofemoral pain. Journal of rehabilitation medicine. 2009 Feb 5;41(3):129-35.

52. Plisky PJ, Gorman PP, Butler RJ, Kiesel KB, Underwood FB, Elkins B. The reliability of an instrumented device for measuring components of the star excursion balance test. North American journal of sports physical therapy: NAJSPT. 2009 May;4(2):92.

53. Watson CJ, Propps M, Ratner J, Zeigler DL, Horton P, Smith SS. Reliability and responsiveness of the lower extremity functional scale and the anterior knee pain scale in patients with anterior knee pain.
Journal of Orthopaedic\& Sports Physical Therapy. 2005 Mar;35(3):136-46.

54. Bijur P, Bérard A, Esses D, Calderon Y, John Gallagher E. Race, Ethnicity, and Management of Pain from Long- bone Fractures: A Prospective Study of Two Academic Urban Emergency Departments. Academic emergency medicine. 2008 Jul 1;15(7):589-97.

55. Jensen MP, McFarland CA. Increasing the reliability and validity of pain intensity measurement in chronic pain patients. Pain. 1993 Nov 1;55(2):195-203.

56. Hina Gupta, Tenzin Yangdon, Ujjwal Gupta, TirveshKumari.Normative Data of Dynamic Balance of Lower Extremities Using Y-Balance Test in Cricketers with 1625 Years of Age. IOSR Journal of Sports and Physical Education. 2016 October; 3[5].

57. Hawker GA, Mian S, Kendzerska T, French M. Measures of adult pain: Visual analog scale for pain (vas pain), numeric rating scale for pain (nrs pain), McGill pain questionnaire (mpq), short-form McGill pain questionnaire (sf-mpq), chronic pain grade scale (cpgs), short form-36 bodily pain scale (sf-36 bps), and measure of intermittent and constant osteoarthritis pain (icoap). Arthritis care \& research. 2011 Nov $1 ; 63(\mathrm{~S} 11)$.

How to cite this article: Kalpana, Muniyan MK, A M R Suresh et.al. Effect of agility and perturbation training on pain, balance and functional ability in subjects with patellofemoral pain syndrome. Int J Health Sci Res. 2021; 11(7): 204-226. DOI: https://doi.org/10.52403/ ijhsr.20210730 